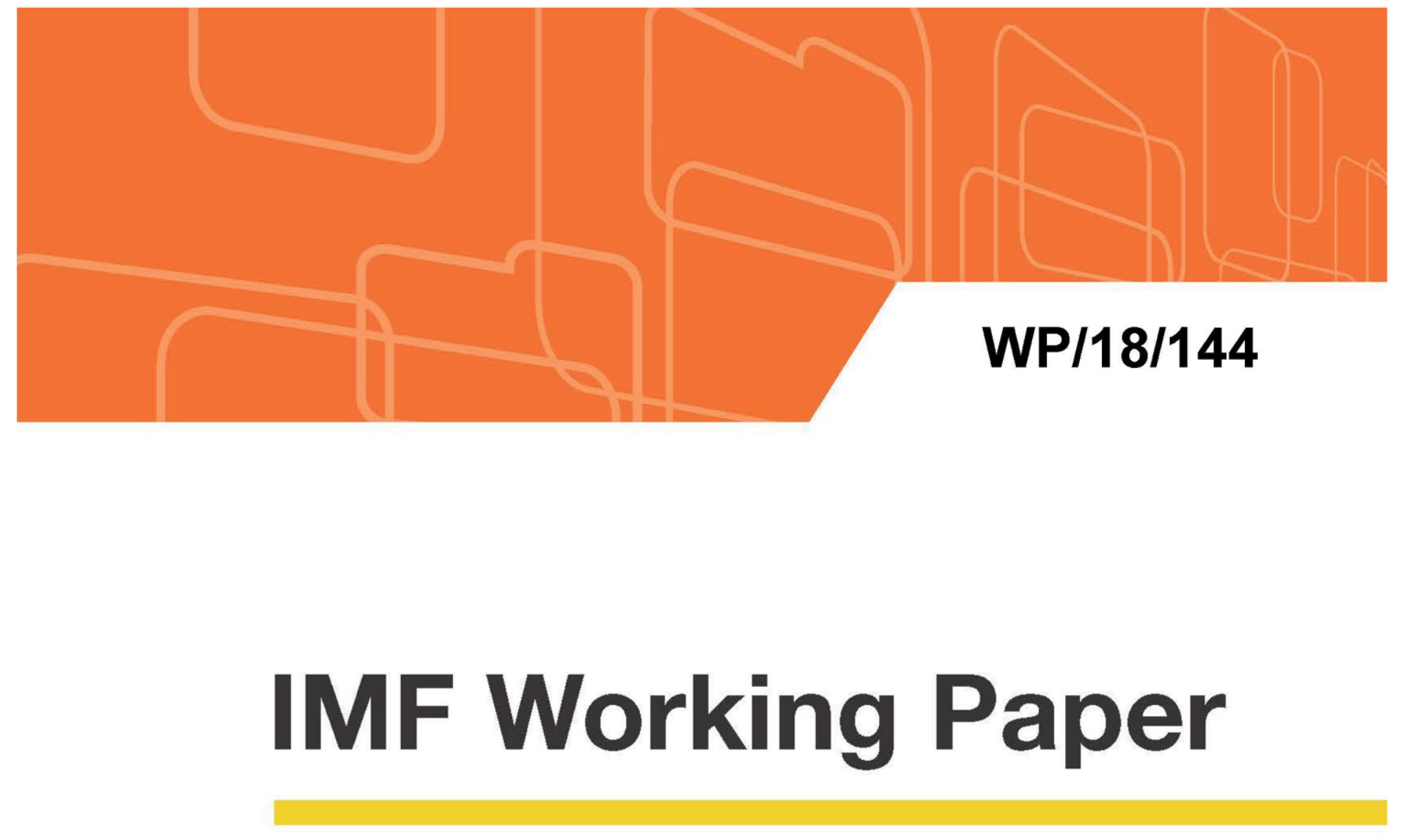

\title{
The Effects of Weather Shocks on Economic Activity: What are the Channels of Impact?
}

\author{
by Sebastian Acevedo, Mico Mrkaic, Natalija Novta, \\ Evgenia Pugacheva, and Petia Topalova
}

IMF Working Papers describe research in progress by the author(s) and are published to elicit comments and to encourage debate. The views expressed in IMF Working Papers are those of the author(s) and do not necessarily represent the views of the IMF, its Executive Board, or IMF management. 


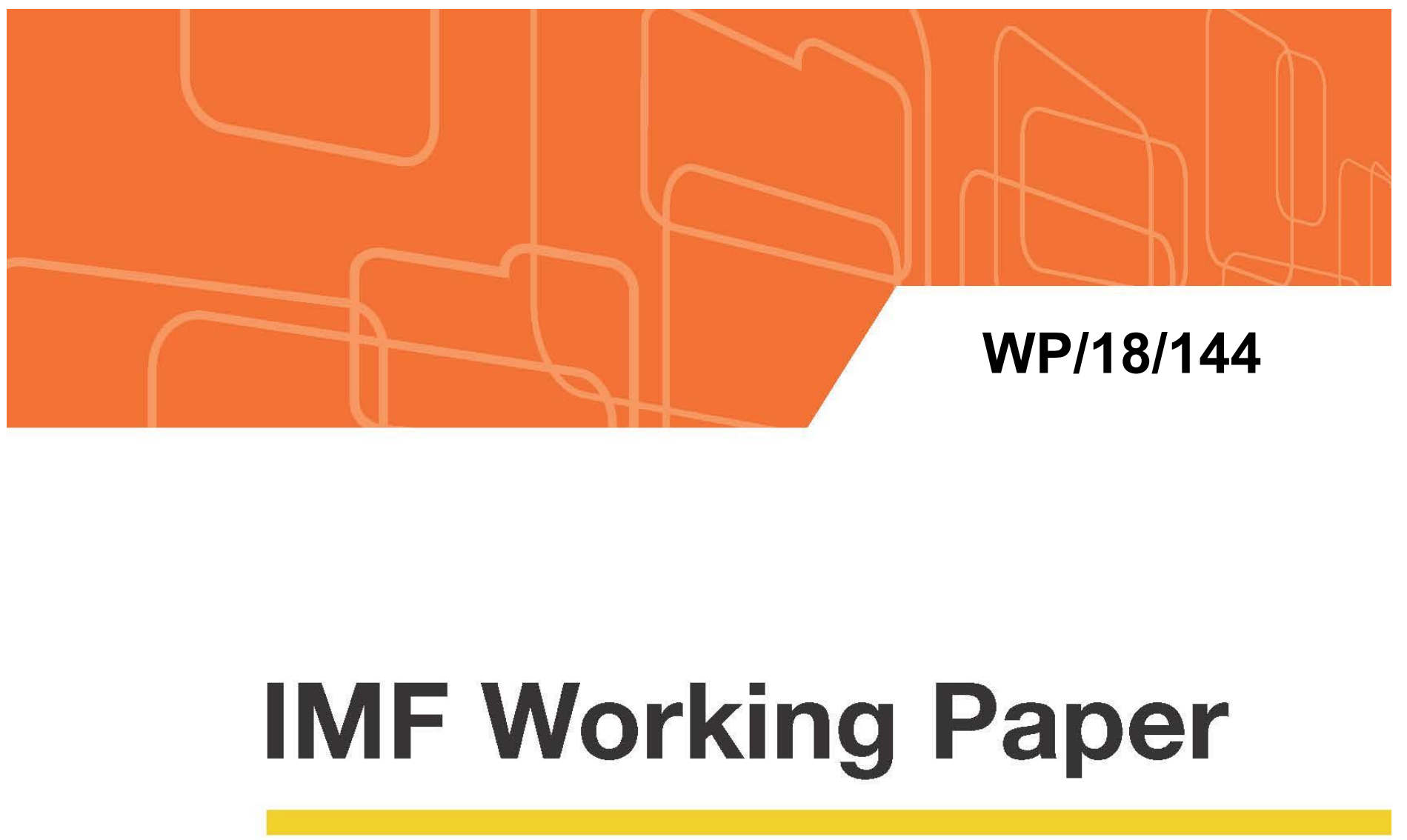

\title{
The Effects of Weather Shocks on Economic Activity: What are the Channels of Impact?
}

\author{
by Sebastian Acevedo, Mico Mrkaic, Natalija Novta, \\ Evgenia Pugacheva, and Petia Topalova
}

IMF Working Papers describe research in progress by the author(s) and are published to elicit comments and to encourage debate. The views expressed in IMF Working Papers are those of the author(s) and do not necessarily represent the views of the IMF, its Executive Board, or IMF management. 


\title{
IMF Working Paper
}

Research Department

\section{The Effects of Weather Shocks on Economic Activity: What are the Channels of Impact? ${ }^{1}$}

\author{
Prepared by Sebastian Acevedo, Mico Mrkaic, Natalija Novta, \\ Evgenia Pugacheva, and Petia Topalova
}

Authorized for distribution by Oya Celasun

June 2018

\begin{abstract}
IMF Working Papers describe research in progress by the author(s) and are published to elicit comments and to encourage debate. The views expressed in IMF Working Papers are those of the author(s) and do not necessarily represent the views of the IMF, its Executive Board, or IMF management.
\end{abstract}

\begin{abstract}
Global temperatures have increased at an unprecedented pace in the past 40 years. This paper finds that increases in temperature have uneven macroeconomic effects, with adverse consequences concentrated in countries with hot climates, such as most low-income countries. In these countries, a rise in temperature lowers per capita output, in both the short and medium term, through a wide array of channels: reduced agricultural output, suppressed productivity of workers exposed to heat, slower investment, and poorer health. In an unmitigated climate change scenario, and under very conservative assumptions, model simulations suggest the projected rise in temperature would imply a loss of around 9 percent of output for a representative low-income country by 2100.

JEL Classification Numbers: E23, O13, Q54, Q56, Q58

Keywords: Climate change, Environoment and growth, Climate policy

Author's E-Mail Address: SAcevedoMejia@imf.org, MMrkaic@imf.org, NNovta@imf.org, EPugacheva@imf.org,PTopalova@imf.org.
\end{abstract}

\footnotetext{
${ }^{1}$ We thank Oya Celasun, Romain Duval, Stéphane Hallegatte, Warwick McKibbin, Edward Miguel, Gian Maria Milesi-Ferretti, Maurice Obstfeld, and Benjamin Olken, as well as participants at the IMF Brown Bag seminar for helpful comments and suggestions. We are grateful for contributions from Manoj Atolia, Claudio Baccianti, Ricardo Marto, and Marcos Poplawski-Ribeiro; and outstanding research assistance from Gavin Asdorian, Olivia Ma, Jilun Xing and Yuan Zeng. An earlier version of the analysis presented in this paper was published in Chapter 3 of the October 2017 World Economic Outlook.
} 


\section{Content}

Abstract__ $\underline{2}$

I. Introduction __ 4

II. Temperature and Precipitation: Historical Patterns and Projections __ 7

III. Empirical Strategy and Data ___

IV. Results__ 12

$\begin{array}{lr}\text { A. Short-term Effect on Per Capita Output } & 12 \\ \text { B. Medium-term Effect on Per Capita Output } & 16 \\ \text { C. Robustness } & 17 \\ \text { V. Channels of Impact } & \frac{17}{24} \\ \text { VI. Long-Term Effects of Temperature Increase-A Model-Based Approach } & \underline{27} \\ \text { VII. Summary and Policy Implications } & \underline{30} \\ \text { Annex 1. Data Sources and Country Groupings } & \underline{31} \\ \text { Annex 2. Model-Based Analysis_ } & \underline{33} \\ \text { References }\end{array}$

\section{Figures}

Figure 1. Average Global Temperature $\underline{4}$

Figure 2. Increase in Average Global Temperature and Contributions of Key Factors ___ 7

Figure 3. Temperature and Precipitation across Broad Country Groups ___

Figure 4. Temperature and Precipitation Projections under the RCP 8.5 Scenario ___ 9

Figure 5. The Contemporaneous Effect of Temperature Increase on Real Per Capita Output 14

Figure 6. Effect of Temperature Increase on Real per Capita Output across the Globe___

Figure 7. Effect of Temprature Increase on Real per Capita Output over Time ___

Figure 8. Effect of Temperature Increase on Sectoral Output Estimated at the

Temperature of the Median Low-Income Developing Country $\underline{18}$

Figure 9. Effect of Temperature Increase on Productivity, Capital, and Labor Input Estimated at the Temperature of the Median Low-Income Developing Country

Figure 10. Long-Term Impact of Temperature Increase for a Representative

Low-Income Developing Country: Model Simulations $\underline{25}$

Figure 11. The Long-Term Impact of Temperature Increase on Real per Capita Output across the Globe

\section{Tables}

Table 1. Effect of Weather Shocks on Output 13

Table 2. Effect of Weather Shocks on Sectoral Output

Table 3. Effect of Weather Shocks in Productivity, Capital and Labor $\underline{22}$

Annex Table 1.1. Data Sourses $\underline{30}$

Annex Table 1.2. Country and Territory Groups $\underline{30}$

Annex Table 2.1 Parameterization of the Debt, Investment, and Growth Model $\underline{31}$ 


\section{INTRODUCTION}

Since the turn of the 20th century, the Earth's average surface temperature has increased significantly. The speed at which this increase has taken place in the past 30 to 40 years appears to be unprecedented in the past 20,000 years (Figure 1). ${ }^{2}$ Most scientists agree that global temperatures are set to rise further, at a scale and pace very much dependent on our ability to restrain greenhouse gas (GHG) emissions, the central cause of global warming (IPCC 2014). Although considerable uncertainty surrounds temperature projections, the scientific consensus predicts that without further action to tackle climate change, average temperatures could rise by $4^{\circ} \mathrm{C}$ or more by the end of the century. Very substantial cuts to current emissions will be needed to limit warming to less than $2^{\circ} \mathrm{C}$. Will climate change have significant macroeconomic consequences, especially in lowincome countries that tend to be more exposed to the vagaries of the weather? And how can these countries cope with the rises in temperature they are set to experience over the coming decades?
Figure 1. Average Global Temperature (Degrees Celsius)

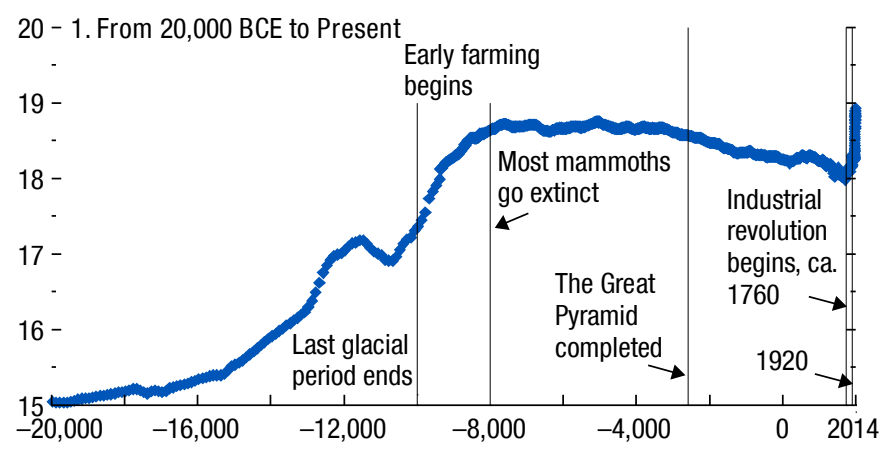

7 - 2. Recent and 21st Century Projections

$6-\quad$ (Deviations from 1880-1910 average)

5 - $\quad$ Observed

- $\quad$ RCP 8.5 mean prediction

4 - $\quad$ RCP 4.5 mean prediction

$3-$

$2-$

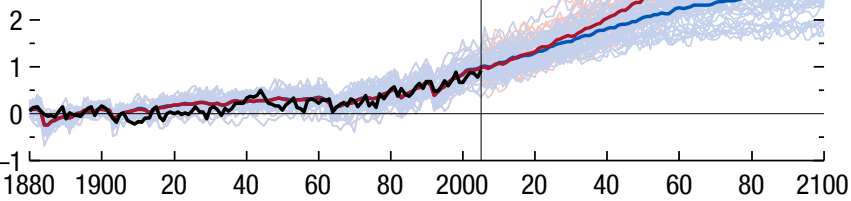

Sources: Intergovernmental Panel on Climate Change (IPCC) Coupled Model Intercomparison Project Phase Five AR5 Atlas subset; Marcott and others (2013); Matsuura and Willmott (2007); National Aeronautics and Space Administration (NASA) Goddard Institute for Space Studies; Royal Netherlands Meteorological Institute Climate Change Atlas; Shakun and others (2012); and IMF staff calculations.

Note: In panel 2, the thin lines represent each of the 40 models in the IPCCWG1 AR5 Annex I Atlas, where a model with different parametrization is treated as a separate model. The thick lines represent the multimodel mean. Representative Concentration Pathways (RCP) are scenarios of greenhouse gas concentrations, constructed by the IPCC. RCP 4.5 is an intermediate scenario, which assumes increased attention to the environment, with emissions peaking around 2050 and declining thereafter. RCP 8.5 is an unmitigated scenario in which emissions continue to rise throughout the 21 st century.

Pinning down the economic consequences of climate change is difficult. Temperature increases of the magnitude that could potentially occur over the next century - and many other aspects of climate change, such as rapid rise in sea levels, ocean acidification and the

\footnotetext{
${ }^{2}$ Climate refers to a distribution of weather outcomes for a given location, while weather refers to a realization from that distribution. Climate change typically implies that the whole distribution of outcomes shifts, with a possible increase in the likelihood of extreme outcomes. As argued by Weitzman (2011), the fattening of the tails - the increase in the probability of potentially irreversible and catastrophic damages - justifies aggressive policy actions to stabilize greenhouse gas (GHG) concentrations in the atmosphere ("climate change mitigation") and adjust to the changing climate ("adaptation").
} 
like — sit well outside recent (and relevant) historical experience and could affect a large number of countries. Extrapolating from historically observed relationship between activity and weather patterns could also be problematic as populations adapt to persistent changes in climate. Yet, studying the macroeconomic effects of annual variation in weather patterns could produce useful insights. ${ }^{3}$ In an influential study, Dell, Jones, and Olken (2012) find that higher temperatures significantly reduce economic growth in low-income countries. Burke, Hsiang, and Miguel (2015a) provide evidence that productivity peaks at about $13^{\circ} \mathrm{C}$ and declines strongly at higher temperatures. Since low-income countries are concentrated in geographic areas with hotter climates, the Burke, Hsiang, and Miguel (2015a) findings suggest that a rise in temperature would be particularly harmful for this set of economies.

In this paper, we provide new evidence on the effects of weather shocks on economic activity, the persistence of these effects and the channels through which they operate. Using data from more than 180 economies over 1950-2015 and following the methodology pioneered by Dell, Jones, and Olken (2012) and Burke, Hsiang and Miguel (2015a), we exploit the annual variation in temperature and precipitation to estimate their causal effect on aggregate economic activity and output of various subsectors of the economy in the short and long run. We study how weather shocks affect the key elements of the aggregate production function, namely productivity, capital accumulation and labor supply, to trace the mechanisms through which weather fluctuations shape aggregate output. Finally, we incorporate the empirical estimates of economic loss from weather shocks and projected changes in temperature into a dynamic general equilibrium model to trace the potential longterm effects of climate change for a typical low-income country.

Our findings suggest that the macroeconomic effect of temperature shocks is uneven across and within countries. Confirming the global nonlinear relationship between annual temperature and growth uncovered by Burke, Hsiang, and Miguel (2015a) in our expanded data set, we find that rising temperatures lower per capita output in countries with relatively high annual average temperature, such as most low-income countries. In these economies, the adverse effect is long-lasting and operates through several channels, namely lower agricultural output, depressed labor productivity in sectors more exposed to the weather, reduced capital accumulation, and poorer human health.

Model simulations suggest that the temperature increase projected by 2100 in a scenario of unmitigated climate change implies significant economic losses for most lowincome economies. Under the conservative assumption that weather shocks have permanent effects on the level, rather than the growth rate, of per capita output, model simulations suggest that the per capita GDP of a representative low-income country would be 9 percent

\footnotetext{
${ }^{3}$ Dell, Jones, and Olken (2014); Heal and Park (2016); and Carleton and Hsiang (2016) provide surveys of the new climate literature, which explores the impact of weather fluctuations on a broad range of economic variables. Dell, Jones, and Olken (2014); Carleton and Hsiang (2016); Hsiang (2016); and Lemoine (2017) discuss the conditions under which empirical estimates of the effect of weather shocks based on historical data can shed light on the consequences of climate change.
} 
lower in 2100 than it would have been in the absence of temperature increases, with the present value of output losses amounting to more than 100 percent of current GDP when discounted at the growth-adjusted rate of 1.4 percent.

Our study contributes to several strands of literature. First, it reexamines the findings of Dell, Jones, and Olken (2012) and Burke, Hsiang, and Miguel (2015) with expanded geographic and temporal coverage, using a more flexible empirical specification, and several sources of weather data. We build on their analysis by examining the channels through which temperature variations affect economic outcomes, using sectoral data to identify productivity effects and infant mortality data to study health impacts. Second, we complement the literature on the effects of weather shocks that previously relied on experiments (see, for example, Seppänen, Fisk and Lei 2006, Niemelä et al. 2002 for the effects on productivity) or within-country studies (see, for example, Barreca 2012, Burgess et al. 2014 for the effect of weather on health outcomes, Schlenker and Roberts 2009, Burke and Emerick 2016, and Wang et al. 2017 for evidence on agricultural output, Deryugina and Hsiang 2014, and Somanathan et al. 2017 for evidence on productivity) and demonstrate that many of the effects uncovered for individual countries or in experimentally controlled settings exist across countries and are important for aggregate outcomes. Finally, we contribute to the large literature that uses models to analyze the effects of natural disasters and climate change on macroeconomic outcomes (Füssel 2010). ${ }^{4}$ Rather than an integrated assessment model (IAM), we use a dynamic general equilibrium model to simulate the potential long-run effects of climate change for a typical low-income country. Existing IAMs are typically not geographically granular enough, lumping together economies with different income levels and average temperatures. They also include various feedback loops between emissions, growth, and climate that are less relevant for low-income countries. The model we use overcomes these concerns and can be easily modified to analyze sectoral issues and structural economic transformation.

The rest of the papers is organized as follows. To set the stage, section II presents some key stylized facts about historical patterns of temperature and precipitations as well as scientific projections of future changes. Section III describes the data and lays out the empirical strategy used to assess the macroeconomic effect of weather shocks. Section IV presents the main findings and several robustness checks of the empirical results, while Section V looks at the channels through which aggregate economic output is affected. Section VI discusses the potential long-run impacts of temperature increase. Section VII concludes summarizing the main findings and policy implications.

\footnotetext{
${ }^{4}$ See also Anthoff and Tol (2010), Hope (2011), Nordhaus and Sztorc (2013) for descriptions of the three bestknown integrated assessment models.
} 


\section{Temperature and Precipitation: Historical Patterns and Projections}

Global temperatures have increased by roughly $1{ }^{\circ} \mathrm{C}$ compared with the 1880-1910 average (Figure 2). ${ }^{5}$ The rise started in earnest in the 1970s, following a large increase in carbon dioxide $\left(\mathrm{CO}_{2}\right)$ emissions. ${ }^{6}$

The increase in average annual temperature has occurred in all regions, with the same accelerating trend starting in the 1970s (Figure 3, panels 1, 3, and 5). The median temperature over the first 15 years of this century, compared with the first 15 years of the past century, was $1.4^{\circ} \mathrm{C}$ higher in advanced economies, $1.3^{\circ} \mathrm{C}$ higher in emerging market economies, and $0.7^{\circ} \mathrm{C}$ higher in low-income countries. Even though most of the warming happened in advanced economies, by 2015 the temperature in the median low-income country $\left(25^{\circ} \mathrm{C}\right)$ was more than twice that of the median advanced economy
Figure 2. Increase in Average Global Temperature and Contributions of Key Factors

(Deviations from 1880-1910 average, degrees Celsius)

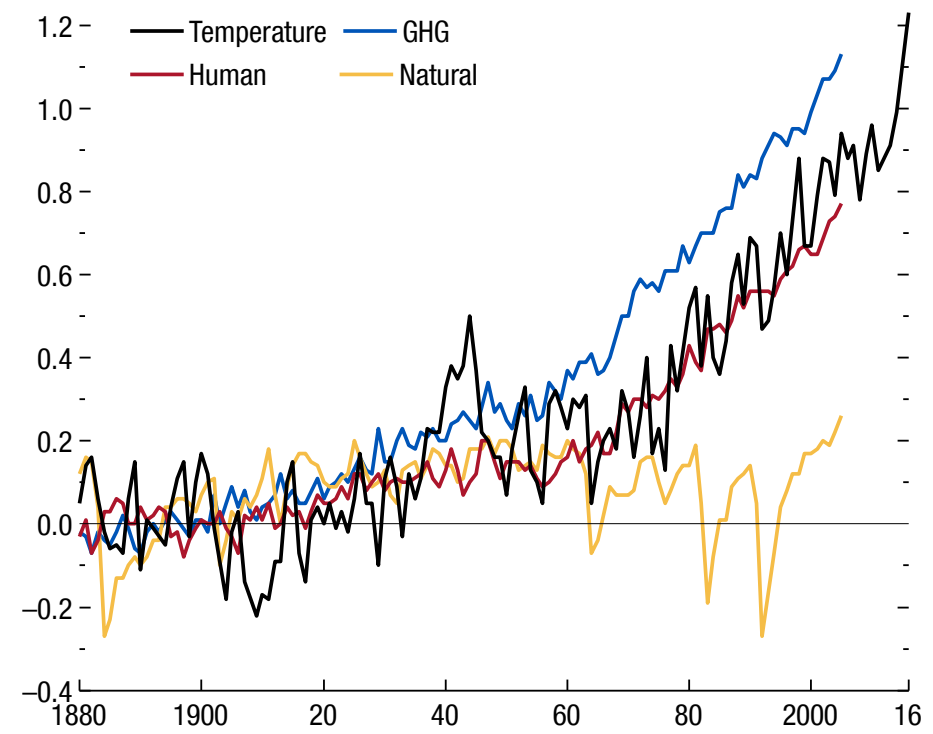

Sources: Carbon Dioxide Information Analysis Center; National Aeronautics and Space Administration (NASA) Goddard Institute for Space Studies; Roston and Migliozzi (2015); and IMF staff calculations.

Note: The lines present the actual increase in land and ocean surface air temperature relative to $1880-1910$ and the increase predicted by different factors. Human factors include land use, ozone emissions, aerosol emissions, and GHG emissions. Natural factors include orbital changes, solar output, and volcanic activity. The contribution of each factor is estimated by "ModelE2" by NASA Goddard Institute for Space Studies. GHG = greenhouse gases.

$\left(11^{\circ} \mathrm{C}\right)$. Trends in precipitation are

generally less clear (Figure 3, panels 2, 4, and 6). Precipitation has increased somewhat in the northern hemisphere since the 1950s, and precipitation in the median low-income country has declined since the 1970 s.

\footnotetext{
${ }^{5}$ A description of the historical and forecast temperature and precipitation series used in the analysis is presented in Section III. Annex 1 lists all data sources, sample coverage and country groupings.

${ }^{6}$ The three most important GHGs, which are regulated under the Kyoto Protocol, are carbon dioxide $\left(\mathrm{CO}_{2}\right)$, methane $\left(\mathrm{CH}_{4}\right)$, and nitrous oxide $\left(\mathrm{N}_{2} \mathrm{O}\right)$. Among those, $\mathrm{CO}_{2}$ has so far been the largest contributor to global warming. Although natural factors explain some of the warming over the past century, according to the Intergovernmental Panel on Climate Change (IPCC) more than half of the temperature increase since 1950 can be attributed to human activity (IPCC 2014). Although $\mathrm{CO}_{2}$ emissions have grown rapidly since the $1950 \mathrm{~s}$ across all income groups, along with rising incomes and populations, emissions from low-income countries are still a fraction of those in advanced and emerging market economies, in both aggregate and per capita terms.
} 
The Intergovernmental Panel on Climate Change (IPCC) constructed four possible scenarios, called Representative Concentration Pathways (RCP), using alternative GHG concentration assumptions to project likely ranges of temperatures over the 21 st century. The rest of the paper focuses on two of these scenarios: an intermediate path (RCP 4.5) and an unmitigated path (RCP 8.5), as shown in Figure 1, panel 2. ${ }^{7}$

Under the RCP 8.5 scenario of unmitigated climate change, the average global temperature by $2081-$ 2100 could rise by $3.7^{\circ} \mathrm{C}$ (with a projected range of $2.6^{\circ} \mathrm{C}-4.8^{\circ} \mathrm{C}$ ). Warming would occur all over the globe, with larger increases over the northern hemisphere, where some regions could experience temperatures almost $12^{\circ} \mathrm{C}$ higher than in 2005 (Figure 4). Between 2005 and 2100, the increase in temperature for the median advanced economy is projected to be $4.4^{\circ} \mathrm{C}$, and $4.5^{\circ} \mathrm{C}$ for the median emerging market economy and median low-income country.

Temperature increases are projected to be smaller in absolute terms closer to the equator, but are very significant when set against the
Figure 3. Temperature and Precipitation across Broad Country Groups

\section{Advanced Economies}

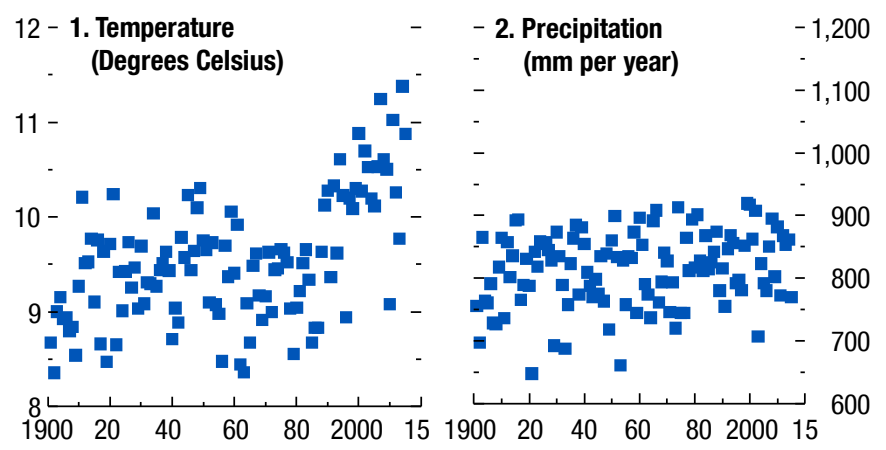

Emerging Market Economies

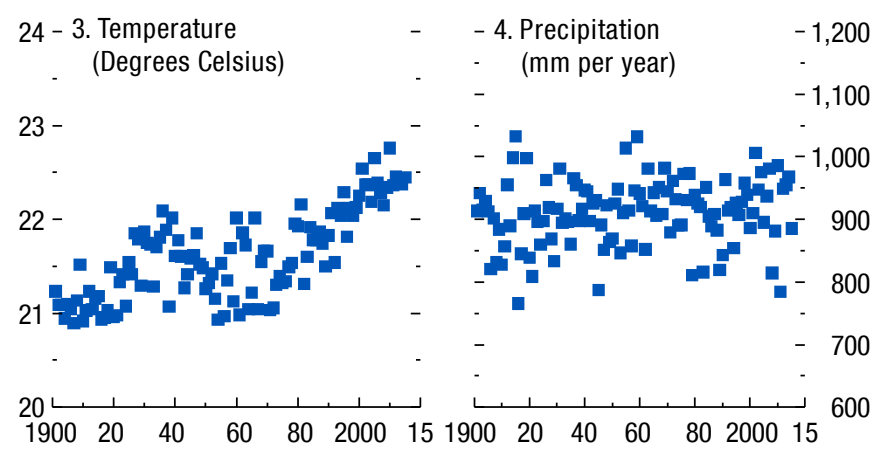

Low-Income Developing Countries

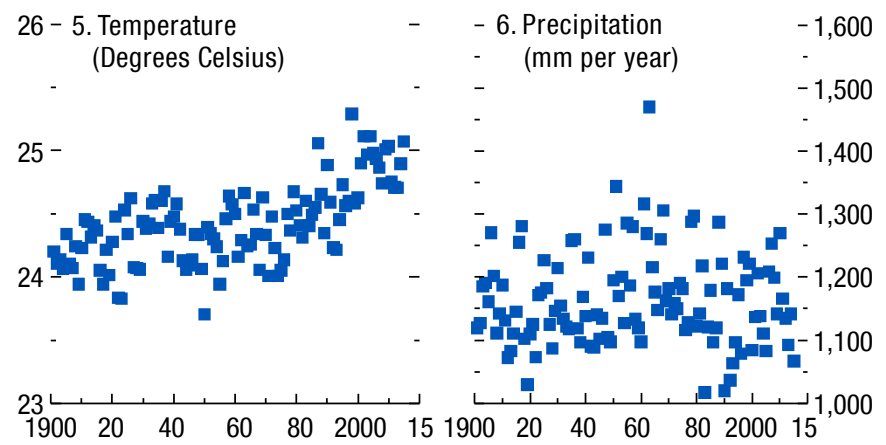

Sources: Climate Research Unit (v. 3.24); and IMF staff calculations. Note: Terrestrial median annual temperature and precipitation data at grid level are aggregated to the country-year level using 1950 population weights. See Annex 1 for data sources and country groupings. $\mathrm{mm}=$ millimeter.

\footnotetext{
${ }^{7}$ The Paris Agreement aims to contain the rise in temperature to less than $2^{\circ} \mathrm{C}$ (ideally to less than $1.5^{\circ} \mathrm{C}$ ) relative to the preindustrial average, which would require policy efforts beyond those assumed in the RCP 4.5 scenario. In the RCP 4.5 scenario, there is increased attention to the environment. $\mathrm{CO}_{2}$ emissions peak around 2050 and decline thereafter, with a resulting temperature increase of $1.8^{\circ} \mathrm{C}$ by $2081-2100$ relative to $1986-2005$
} 
Figure 4. Temperature and Precipitation Projections under the RCP 8.5 Scenario
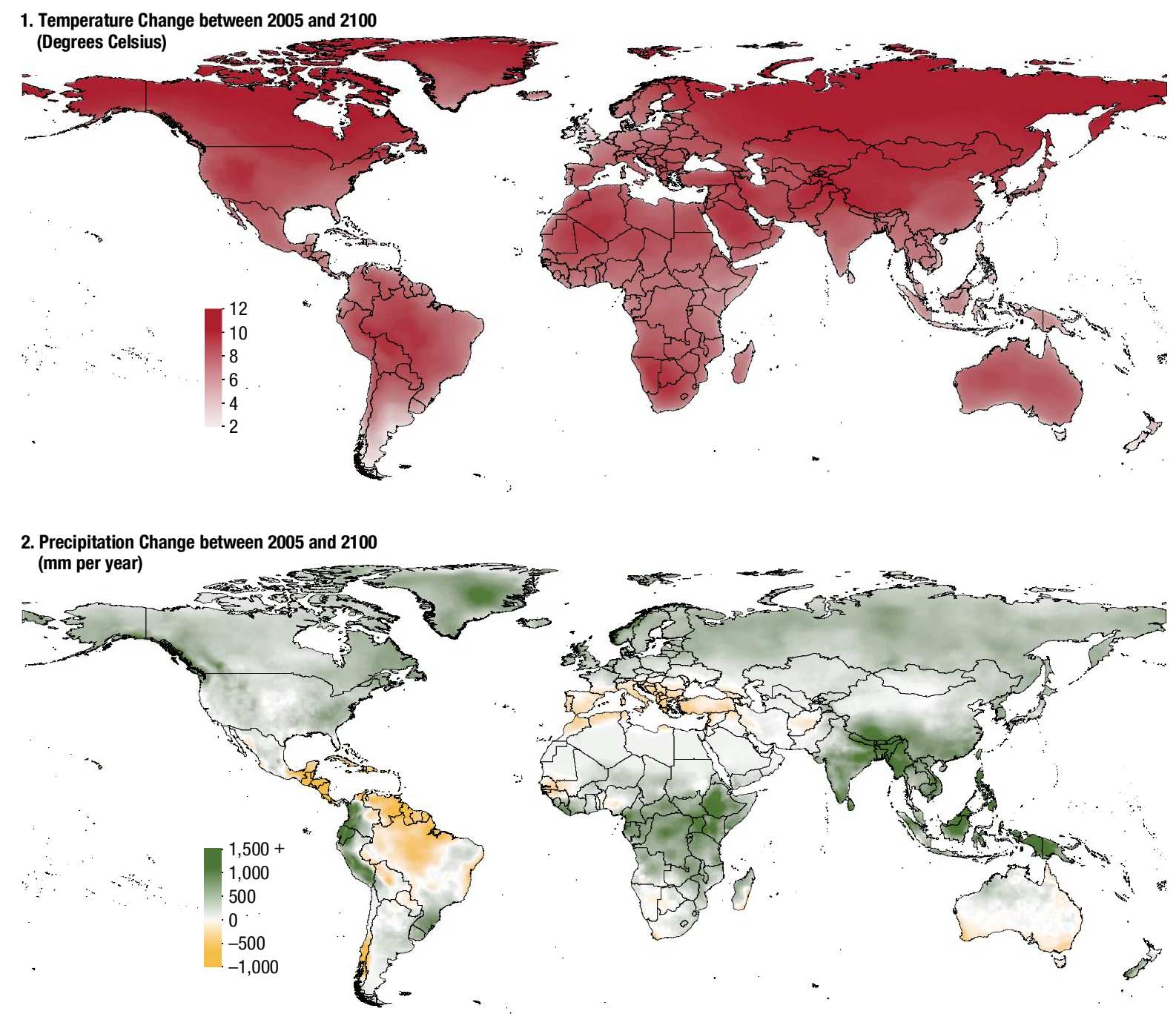

Sources: National Aeronautics and Space Administration (NASA) Earth Exchange Global Daily Downscaled Projections (NEX-GDDP); World Bank Group Cartography Unit; and IMF staff calculations.

Note: The NEX-GDDP data set comprises downscaled climate scenarios for the globe that are derived from the General Circulation Model (GCM) runs conducted under the Coupled Model Intercomparison Project Phase 5 (CMIP5) and for two Representative Concentration Pathways (RCP) greenhouse gas emissions scenarios (4.5 and 8.5). The CMIP5 GCM runs were developed for the Intergovernmental Panel on Climate Change Fifth Assessment Report. The data set includes downscaled projections from the 21 models and scenarios for daily maximum temperature, minimum temperature, and precipitation for 1950-2100. The spatial resolution of the data set is 0.25 degrees $(\sim 25 \mathrm{~km} \times 25 \mathrm{~km})$. mm = millimeter.

historical year-to-year and intrayear variability in temperature observed in those locations. For example, the historically observed natural year-to-year temperature variability for countries located in the tropics is roughly $0.5^{\circ} \mathrm{C}$. The projected increase in temperature for these countries between 2005 and 2100 under the extreme unmitigated climate change scenario is $4.1^{\circ} \mathrm{C}$ - in other words, more than 8.5 times larger than the current natural variability, implying a totally new climatic regime (see also World Bank 2013). Change in

(a likely range of $1.1^{\circ} \mathrm{C}$ to $2.6^{\circ} \mathrm{C}$ and a greater than 50 percent chance of an increase exceeding $2^{\circ} \mathrm{C}$ by 2100 ). In the RCP 8.5 scenario, $\mathrm{CO}_{2}$ emissions grow throughout the 21 st century. 
precipitation is projected to vary by region, with dry areas generally expected to become drier and wet regions expected to experience an increase in rainfall.

\section{EMPIRICAL STRATEGY AND DATA}

In the absence of historical experience with climate change that may be relevant for countries today, we build on existing literature and identify how annual fluctuations in temperature and precipitation affect macroeconomic performance. Using the approach of Dell, Jones, and Olken (2012) and Burke, Hsiang, and Miguel (2015a), we use withincountry and across-country year-to-year fluctuations in temperature and precipitation to identify their causal effect on aggregate outcomes, both contemporaneously and over the medium term. We build on these studies by expanding the geographic and temporal coverage of the analysis to more than 180 economies during 1950-2015 (see Annex 1 for a list of countries and territories), examining the effects of weather shocks on a larger set of outcome variables, establishing the robustness of findings to different sources of weather data and alternative, more flexible empirical specifications.

We use Jordà's (2005) local projection method to trace out the impulse response function of real per capita GDP to a weather shock. This approach was advocated by Stock and Watson (2007), among others, as a flexible alternative that does not impose the dynamic restrictions embedded in vector autoregressions or autoregressive distributed lag specifications and is particularly suited to estimating nonlinearities in the dynamic response. We derive the impulse response by estimating a set of regressions:

$$
\begin{aligned}
y_{i, t+h}-y_{i, t-1}=\beta_{1}^{h} c_{i, t}+\beta_{2}^{h} c_{i, t}^{2}+\gamma_{1}^{h} c_{i, t-1} & +\gamma_{2}^{h} c_{i, t-1}^{2}+\sum_{j=1}^{h-1} \delta_{1}^{h} c_{i, t+h-j}+\sum_{j=1}^{h-1} \delta_{2}^{h} c_{i, t+h-j}^{2} \\
& +\varphi_{1}^{h} \Delta y_{i, t-1}+\mu_{i}^{h}+\theta_{r, t}^{h}+\varepsilon_{i, t}^{h},
\end{aligned}
$$

in which $i$ indexes countries, $t$ indexes years, and $h$ indexes the estimation horizon (from horizon 0 , which captures the contemporaneous effect, up to horizon 7 , which captures the effect 7 years after the shock). Regressions for each horizon are estimated separately. The dependent variable is the cumulative growth of the outcome of interest between horizons $t-$ 1 and $t+h$, measured as difference in the natural logarithms $\left(y_{i, t}\right)$. Following Burke, Hsiang, and Miguel (2015a), the estimated regression has a quadratic specification in the weather variables, $c_{i, t}$, which comprise average annual temperature and precipitation. The regressions control for one lag of the dependent and weather variables and for forwards of the weather variables, as suggested by Teulings and Zubanov (2014). Country fixed effects $\left(\mu_{i}^{h}\right)$ control for all time-invariant country differences, such as latitude and average growth rates, while time fixed effects interacted with region dummies $\left(\theta_{r, t}^{h}\right)$ control for the common effect of all annual shocks across countries within a region. ${ }^{8}$ The analysis also explores an alternative

\footnotetext{
${ }^{8}$ We use indicators for six regions as defined by the World Bank: East Asia and Pacific, Europe and Central Asia, Latin American and the Caribbean, Middle East and North Africa, North America, South Asia, and SubSaharan Africa.
} 
fixed-effects structure proposed by Burke, Hsiang, and Miguel (2015a), which includes time fixed effects $\left(\tau_{i}^{h}\right)$ and country-specific linear and quadratic time trends $\left(\theta_{i}^{h} t+\theta_{i}^{h} t^{2}\right)$ to account for within-country changes over time, such as demographic shifts, instead of the region-year fixed effects $\left(\theta_{r, t}^{h}\right)$ of the baseline specification. Standard errors are clustered at the country level.

To avoid bias associated with "bad controls" (or overcontrolling), the specification is purposefully parsimonious: many of the determinants of growth, typically included in standard growth regressions (for example, institutional quality, educational achievement, policies, and so forth), may themselves be shaped by weather shocks and are thus not part of the baseline estimation. Of course, to the extent that these are time-invariant and countryspecific, they are subsumed in the country fixed effects.

Within this estimation framework, the effect of a weather shock, such as a $1{ }^{\circ} \mathrm{C}$ increase in temperature, on the level of output at horizon $h$ can be obtained by differentiating equation (1) with respect to temperature:

$$
\frac{\partial\left(y_{i, t+h}-y_{i, t-1}\right)}{\partial T_{i, t}}=\beta_{1}^{h}+2 \beta_{2}^{h} T_{i, t} .
$$

Evaluating equation (2) for each horizon separately and using the 2015 annual average temperature, $T_{i, 2015}$, allows us to obtain the impulse response functions of per capita GDP to a temperature shock for each country. The marginal effect of an increase in precipitation is computed analogously. The threshold temperature at which the effect on the outcome variable switches from positive to negative, that is, the optimal level of temperature for per capita output, can be obtained by setting equation (2) to zero.

As discussed below, we use this empirical framework to examine the effect of weather shocks on per capita GDP, as well as on sectoral output (crop production, agricultural value added, services value added, and industrial value added), and the key elements of the aggregate production function (investment as a proxy for capital stock, infant mortality and the human development index as a proxy for labor supply). We rely on an extended version of this empirical strategy to capture productivity effects using more disaggregated data on industry outcomes.

Our primary data sources for the outcome variables are the IMF World Economic Outlook and the World Bank World Development Indicators databases, from which we construct our measures of per capita GDP, broad sectoral value added and index of agricultural production. We rely on the Groningen Growth and Development Centre 10sector database for more disaggregated data on sectoral real value added and employment in 40 countries over the period 1950-2012 when analyzing productivity effects.

Historical temperature and precipitation are from the University of East Anglia's Climate Research Unit (CRU). We construct average annual temperature and precipitation by aggregating weather data at the grid-cell level, provided by CRU at $0.5 \times 0.5$-degree resolution, to the level of the country using the 1950 population in each cell as weights. This method allows us to account for differences in population density within countries and 
captures the average weather experienced by a person in the country. Projections of temperature and precipitation are from the NASA Earth Exchange Global Daily Downscaled Projections dataset, which provides projections of the daily maximum and minimum temperature and total precipitation from 2005 and projections for $2015-2100$ at the $0.25 \mathrm{x}$ 0.25 degree resolution from the 21 models of the Coupled Model Intercomparison Project Phase 5 for the RCP 4.5 and RCP 8.5 scenario. For each of these scenarios, we compute annual temperatures by (i) averaging the maximum and minimum daily temperatures for each model, (ii) averaging across the 21 models, and (iii) averaging across all days of the year. We construct projections for annual precipitation in a similar fashion, but take the sum of the daily precipitation forecast. Annex 1 lists all data sources used in the paper.

\section{RESUlTS}

\section{A. Short-term Effect on Per Capita Output}

The results from estimating equation (1) are presented in Table 1. The main specification is given in column (5), while the other columns present results of robustness checks to using alternative sources of weather data; alternative population weights; and alternative samples, controls, and estimation approaches. Panel A contains the estimated coefficients for the weather variables at horizon 0 (that is, the contemporaneous effects of weather shocks). Panel B shows the effect of a $1^{\circ} \mathrm{C}$ increase in temperature estimated, following equation (2), at the median 2015 temperature for advanced economies (median $\mathrm{T}=$ $11^{\circ} \mathrm{C}$ ), emerging market economies (median $\mathrm{T}=22^{\circ} \mathrm{C}$ ), and low-income countries (median $\mathrm{T}$ $=25^{\circ} \mathrm{C}$ ) on impact and after seven years. Similarly, Panel C shows the effect of a 100 millimeter increase in precipitation estimated at the median 2015 precipitation for the three groups of economies on impact and after seven years.

Across all specifications, we find that the estimated coefficient on temperature is positive and the coefficient on temperature squared is negative, confirming the nonlinear relationship between growth and temperature shocks uncovered by Burke, Hsiang, and Miguel (2015a). At low temperatures, an increase in temperature boosts growth, whereas at high temperatures, an increase in temperature hurts growth, with the threshold average annual temperature estimated to be about $13^{\circ} \mathrm{C}-15^{\circ} \mathrm{C}$. These results suggest highly uneven effects of warming across the globe, depending on the initial climate of a particular location. 
Table 1. Effect of Weather Shocks on Output

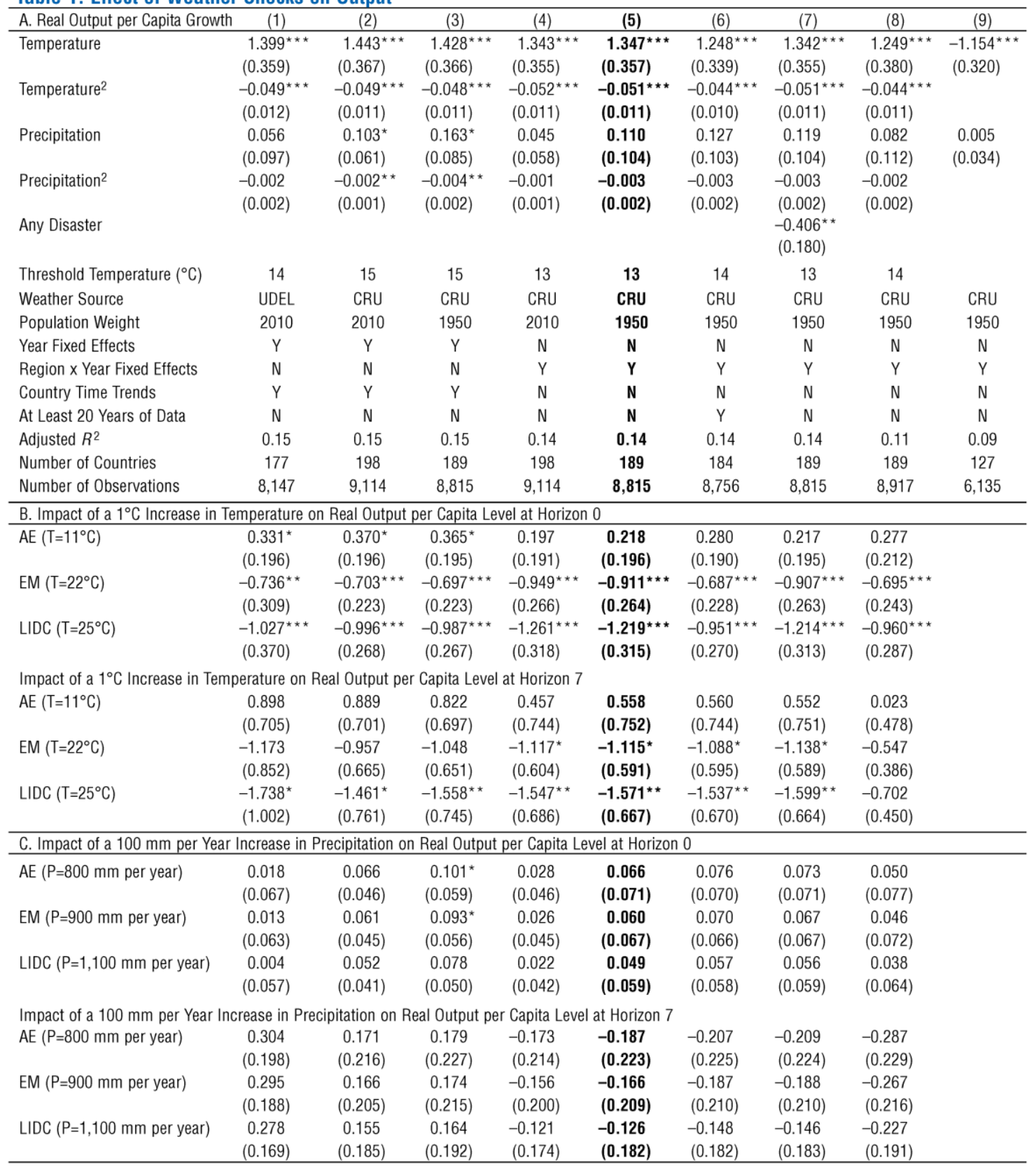

Source: IMF staff calculations.

Note: The table presents results from estimating equation (1), with separate regressions for each horizon. Panel A reports the estimated coefficients on the weather variables for horizon 0. Panels $B$ and $C$ show the marginal impact of a change in temperature and precipitation computed as per equation (2) at the median temperature $(T)$ and median precipitation (P) of advanced economies (AE), emerging markets (EM), and low-income developing countries (LIDC) contemporaneously (horizon 0 ) and cumulatively seven years after the shock. The specifications in columns (1)-(8) control for country fixed effects; lags and forwards of temperature, precipitation, and their squared terms; and lag of growth. Column (8) shows results from estimating an autoregressive distributed lag model with seven lags of the weather variables and their squared terms. Column (9) reports the coefficients on temperature and precipitation from a linear specification estimated on a sample of countries with average temperature above $15^{\circ} \mathrm{C}$, also including controls for country fixed effects and lag of growth. In all specifications, standard errors are clustered at the country level. CRU = University of East Anglia, Climate Research Unit; mm = millimeter; UDEL = University of Delaware.

${ }^{\star} p<0.1 ;{ }^{\star \star} p<0.05 ;{ }^{\star \star \star *} p<0.01$. 
Because most advanced economies are situated in colder locations, with annual average temperatures close to the $13^{\circ} \mathrm{C}-15^{\circ} \mathrm{C}$ threshold, a marginal temperature increase does not materially affect their contemporaneous growth. ${ }^{9}$ Conversely, emerging market economies and particularly low-income countries tend to have much hotter climates, and a rise in temperature significantly lowers per capita GDP.

Figure 5 illustrates these findings, by overlaying the marginal effect of a $1^{\circ} \mathrm{C}$ increase in temperature on contemporaneous per capita GDP by initial temperature, with the distribution of advanced, emerging market and low-income countries according to their average annual temperature. For the median emerging market economy, a $1{ }^{\circ} \mathrm{C}$ increase from a temperature of $22^{\circ} \mathrm{C}$ lowers growth in the same year by 0.9 percentage point. For the median low-income country, with temperature of $25^{\circ} \mathrm{C}$, the effect is even larger: growth falls by 1.2 percentage points. And even though countries projected to be significantly affected by an increase in temperature produced only about one-fifth of global GDP in 2016, they are home to close to 60 percent of current global population, as depicted in Figure 6, panel 2, which rescales countries in proportion to their population.
Figure 5. The Contemporaneous Effect of Temperature Increase on Real per Capita Output

(Percent; temperature on $x$-axis)
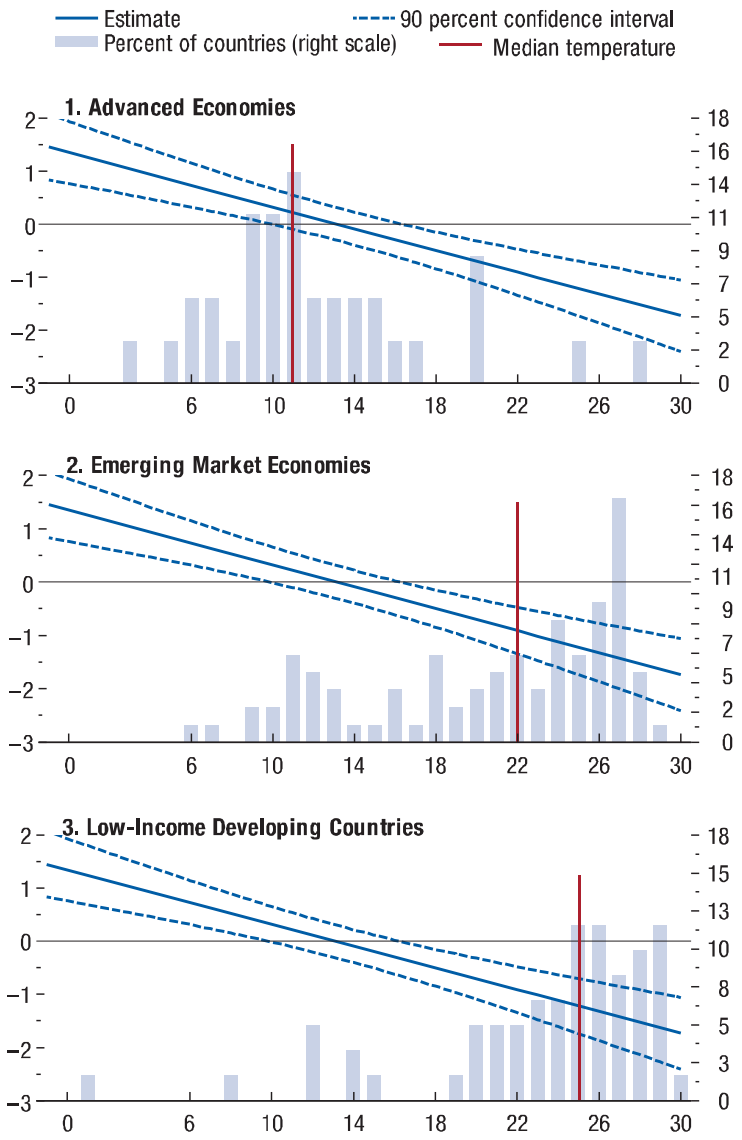

Source: IMF staff calculations.

Note: The panels superimpose the contemporaneous effect of a $1^{\circ} \mathrm{C}$ increase in temperature on per capita output at different temperature levels computed as per equation (1) over the distribution of average annual temperatures recorded in 2015 in advanced economies, emerging markets and low-income countries. The blue lines show the point estimates and 90 percent confidence intervals, while the light blue bars denote the percent of countries at each temperature level. The vertical red line is the median temperature for the country group.

\footnotetext{
${ }^{9}$ Even if the effects of an increase in temperature on overall GDP in these countries are estimated to be negligible, this may mask large losses and gains across sectors. Moreover, the analysis focuses on the macroeconomic effects of a limited set of weather characteristics, namely temperature and precipitation. The negative impact of other aspects of the climate, such as the rise of sea levels or the occurrence of extreme weather events, may be less unequal across broad income groups (see for example Box 3.1 of Chapter 3 of theOctober 2017 World Economic Outlook). The estimates also abstract from potential spillovers to advanced economies from famines, epidemics, social conflicts, and other difficult-to-predict effects of weather shocks in vulnerable economies.
} 
Figure 6. Effect of Temperature Increase on Real per Capita Output across the Globe (Percent)

1. Effect of a $1^{\circ} \mathrm{C}$ Increase in Temperature on Real per Capita Output at the Grid Level

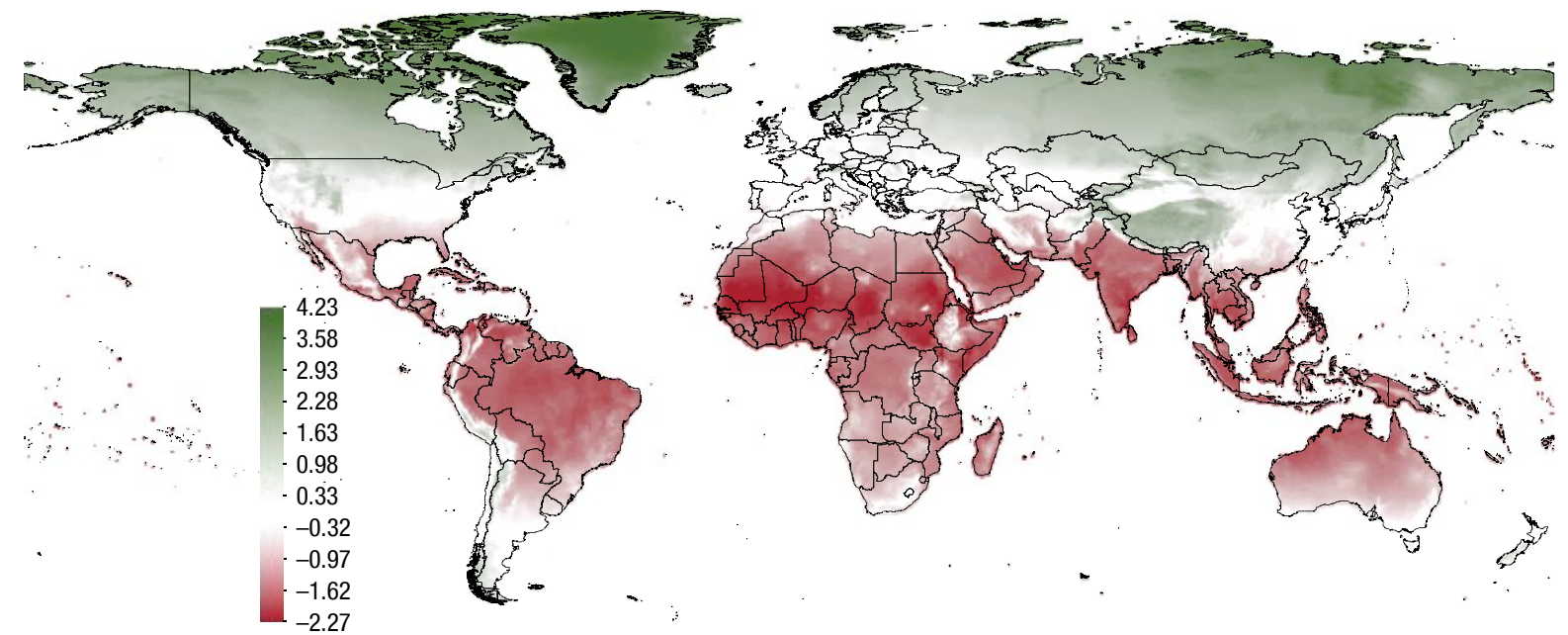

2. Effect of a $1^{\circ} \mathrm{C}$ Increase in Temperature on Real per Capita Output at the Country Level, with Countries Rescaled in Proportion to Their Population

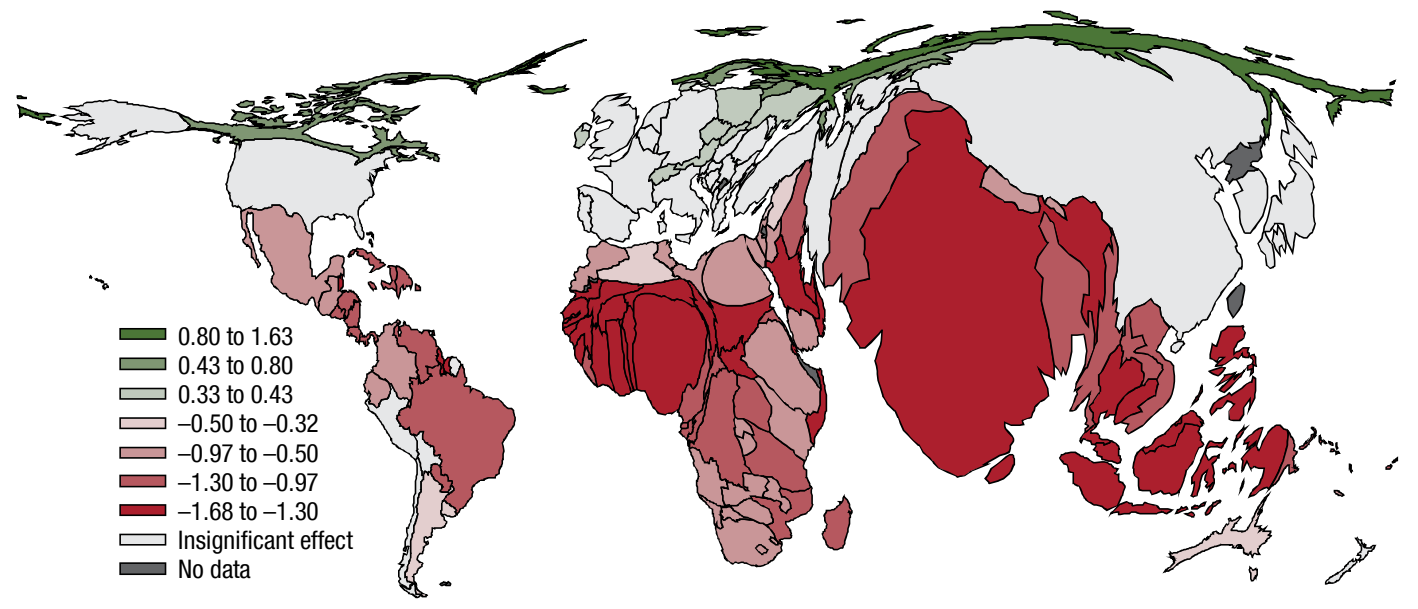

Sources: Natural Earth; ScapeToad; United Nations World Population Prospects Database: the 2015 Revision; World Bank Group Cartography Unit; and IMF staff calculations.

Note: The maps depict the contemporaneous effect of a $1^{\circ} \mathrm{C}$ increase in temperature on per capita output computed as per equation (2). Panel 1 uses 2005 gridlevel temperature, while panel 2 uses the recent 10-year average country-level temperature together with estimated coefficients in Table 1, column (5). In the cartogram in panel 2, each country is rescaled in proportion to its 2015 population. Gray areas indicate the estimated impact is not statistically significant.

There is also significant variation in the impact of temperature increase within countries. Figure 6, panel 1 , shows the estimated impact of a $1^{\circ} \mathrm{C}$ increase in temperature across all grids in the world, based on their average annual temperature in 2005. As indicated on the map, in a number of economies where the effect on aggregate growth may be statistically indistinguishable from zero, such as the United States, there are areas where a temperature rise would significantly lower output.

Our analysis reveals no consistently significant relationship between precipitation and per capita GDP growth across the various specifications as indicated in Panel C in Table 1. The lack of robust relationship could reflect potentially larger measurement error in the 
precipitation variable as discussed in Auffhammer et al. (2011). The measurement error may be further amplified by temporal aggregation. For example, if the only channel through which precipitation affects aggregate outcomes is through its effect on agriculture, then only precipitation during crops' growing period-poorly proxied by annual precipitation - may be relevant.

\section{B. Medium-term Effect on Per Capita Output}

The empirical analysis suggests that the effects of temperature increase are long-lasting. Economic activity in countries with warmer climates does not recover quickly after a rise in temperature. The cumulative effects of a $1{ }^{\circ} \mathrm{C}$ increase in temperature seven years after the shock is shown in the lower half of Panel B in Table 1. Even seven years after a weather shock, per capita output is 1 percent lower for the median emerging market economy and 1.5 percent lower for the median lowincome country as depicted in Figure 7.

The estimated persistence may reflect the relatively persistent nature of temperature shocks. Univariate time series regression analysis shows that
Figure 7. Effect of Temperature Increase on Real per Capita Output over Time

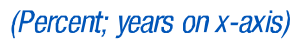

(Percent; years on $x$-axis)
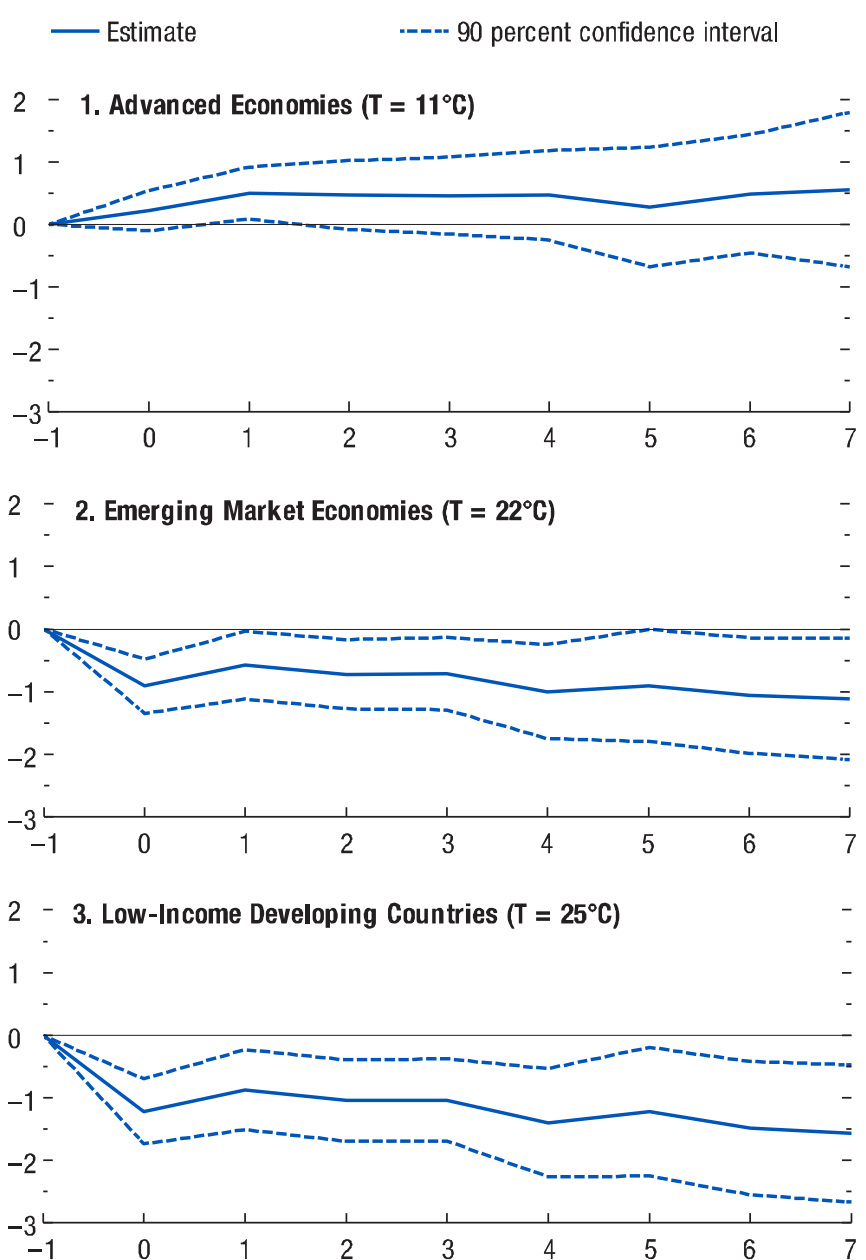

Source: IMF staff calculations.

Note: The panels depict the impulse response of per capita output to a $1^{\circ} \mathrm{C}$ increase in temperature estimated at the median temperature of advanced economies, emerging markets and low-income developing countries. Horizon 0 is the year of the shock. $T=$ temperature.

temperature shocks decay slowly, especially in relatively hot locations, with a $1^{\circ} \mathrm{C}$ degree increase in annual temperature leading to significantly higher temperatures in the subsequent years. A deepening in the shape of the estimated impulse response of output to a temperature shock hints at the possibility of a growth effect (and consequently much larger economic losses from higher temperatures). However, statistically, we are unable to reject the 
hypothesis that the contemporaneous and medium-term effects of a temperature shock on per capita output are identical. ${ }^{10}$

\section{Robustness}

To establish the robustness of these findings, we present results from estimating numerous alternative specifications in Table 1. In column (1), we replicate the specification of Burke, Hsiang, and Miguel (2015a), using our substantially larger sample (relative to their study, our paper expands the sample both geographically and temporally by about 25 percent). In this specification, we include country-specific linear and quadratic time trends, we use University of Delaware (UDEL) weather data, and aggregate weather variables using the 1990 population weights. Column (2) uses the same empirical approach as in column (1) but an alternative source of weather data, CRU instead of UDEL, and obtains similar coefficients on the temperature and precipitation variables.

The choice of population weights used to aggregate gridded weather data to the country level could play an important role since migration within and across country borders is one of the potential strategies for coping with adverse weather conditions. Since historical data show an increase in average annual temperatures starting in the 1970s (Figure 3), column (3) presents results with 1950 population weights to account for migration responses that could have already taken place.

Column (4) and column (5) (main specification for the paper) present results for the baseline specification with region-year fixed effects, following Dell, Jones, and Olken 2012, using 2010 and 1950 population weights, respectively. Column (6) limits the sample to countries with at least 20 years of data. Column (7) controls separately for the occurrence of natural disasters since temperature and precipitation fluctuations might affect economic activity through their effect on the incidence of natural disasters. Controlling for natural disasters does not materially alter the estimated coefficients on temperature and precipitation. In columns (1)- (7), impulse responses were estimated using Jordà's (2005) local projection method. Column (8), however, tests the robustness of the findings to using the autodistributed lag model with seven lags of the weather variables and their squared terms, as in Dell, Jones, and Olken (2012), who tested different models from no lags up to 10 lags and found that across different lag specifications results are broadly consistent in magnitude and statistical significance.

\section{Channels OF IMPaCT}

The weather can influence economic activity through various channels. The most obvious one is agricultural output, given that temperature and precipitation are direct inputs in crop production. However, studies show evidence of broader impacts, including on labor

\footnotetext{
${ }^{10}$ Dell, Jones, and Olken (2012) and Burke, Hsiang, and Miguel (2015a) argue in favor of a growth effect, although it is difficult to pin down the precise channel through which weather shocks persistently influence economic growth.
} 
productivity, mortality, health, and conflict. ${ }^{11}$ The literature so far has often studied these effects within a specific country or through laboratory experiments. We examine whether these channels are also at work in a cross-country setting.

\section{Sectoral Output: Agriculture, Manufacturing, Services}

We begin by studying whether weather shocks influence only agricultural production or also affect other economic sectors, by estimating equation (1) but with real value added of agricultural, manufacturing, and services sectors, and crop production as our outcomes of interest. Regression results are presented in Table 2. Figure 8 depicts the impulse response function of the four outcomes considered at the temperatures prevailing in the median low-income country.

We find that agricultural value added and crop production drop with higher temperature, recover somewhat in subsequent years, but generally remain depressed over the medium term - much as expected and as documented in a large body of work. ${ }^{12}$ However, the analysis also confirms findings that manufacturing output is similarly hurt as temperatures rise in countries with hot climates, although the estimates are more imprecise (see also Dell, Jones, and Olken 2012; Burke, Hsiang, and Miguel 2015a). Only services sector output appears to be sheltered from the weather.
Figure 8. Effect of Temperature Increase on Sectoral Output Estimated at the Temperature of the Median Low-Income Developing Country

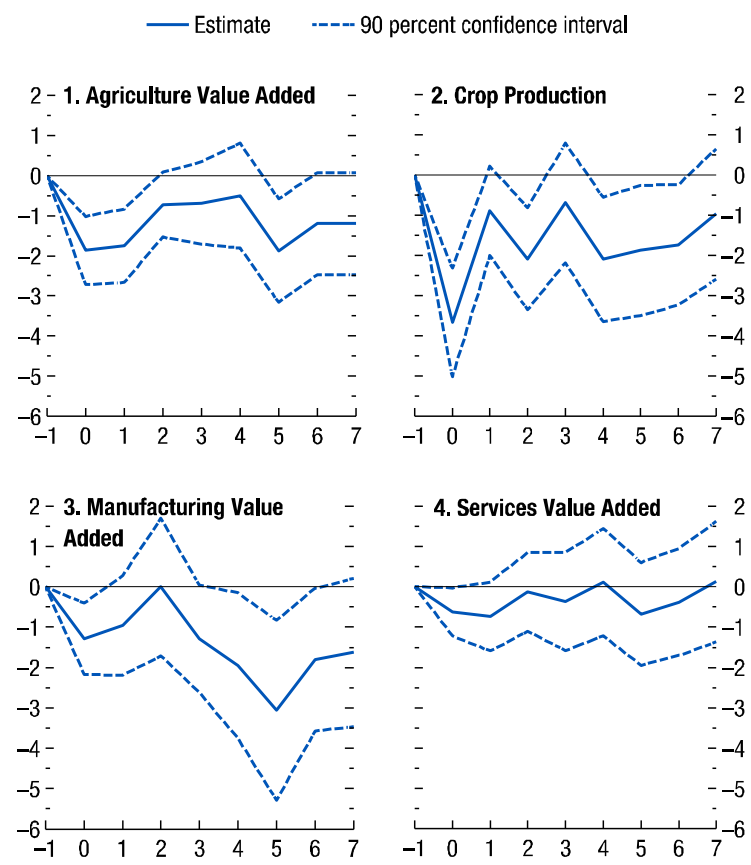

Source: IMF staff calculations.

Note: The panels depict the effect of a $1^{\circ} \mathrm{C}$ increase in temperature estimated at the median low-income developing country temperature $\left(25^{\circ} \mathrm{C}\right)$. Horizon 0 is the year of the shock. Crop production is an index, produced by the Food and Agriculture Organization, of price-weighted quantities of agricultural commodities produced excluding production for seeds and fodder.

\footnotetext{
${ }^{11}$ See Dell, Jones, and Olken (2014); Heal and Park (2016); and Carleton and Hsiang (2016) for literature reviews. Weather shocks can also indirectly affect economic activity through their impacts on third markets. See Cashin, Mohaddes, and Raissi (2017) for an analysis of the international macroeconomic transmission of El Niño within a dynamic multicountry framework.

${ }^{12}$ See, among others, Barrios, Bazoumana, and Strobl (2008); Barrios, Bertinelli, and Strobl (2006, 2010); Schlenker and Lobell (2010); Feng, Krueger, and Oppenheimer (2010); Lobell, Schlenker, and Costa-Roberts (2011); and Lanzafame (2014) for evidence from emerging market and developing economies and Schlenker and Roberts (2009), Burke and Emerick (2016) and Wang et al. (2017) for evidence from the United States.
} 
Table 2. Effect of Weather Shocks on Sectoral Output

\begin{tabular}{|c|c|c|c|c|}
\hline A. Dependent Variable & $\begin{array}{c}\text { Agriculture } \\
\text { (1) }\end{array}$ & $\begin{array}{c}\text { Manufacturing } \\
\text { (2) }\end{array}$ & $\begin{array}{c}\text { Services } \\
\text { (3) }\end{array}$ & $\begin{array}{c}\text { Crop Production } \\
\text { (4) }\end{array}$ \\
\hline Temperature & $\begin{array}{c}0.283 \\
(0.871)\end{array}$ & $\begin{array}{c}1.281 \\
(1.035)\end{array}$ & $\begin{array}{c}-0.268 \\
(0.585)\end{array}$ & $\begin{array}{c}3.860^{*} \\
(2.085)\end{array}$ \\
\hline Temperature ${ }^{2}$ & $\begin{array}{c}-0.043^{*} \\
(0.023)\end{array}$ & $\begin{array}{l}-0.051^{*} \\
(0.027)\end{array}$ & $\begin{array}{l}-0.007 \\
(0.016)\end{array}$ & $\begin{array}{l}-0.151^{* * *} \\
(0.050)\end{array}$ \\
\hline Precipitation & 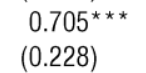 & $\begin{array}{c}0.108 \\
(0.149)\end{array}$ & $\begin{array}{c}-0.000 \\
(0.111)\end{array}$ & 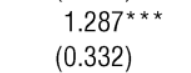 \\
\hline Precipitation ${ }^{2}$ & $\begin{array}{l}-0.015^{\star * *} \\
(0.005)\end{array}$ & $\begin{array}{l}-0.002 \\
(0.003)\end{array}$ & $\begin{array}{c}-0.001 \\
(0.002)\end{array}$ & $\begin{array}{l}-0.028^{* * *} \\
(0.007)\end{array}$ \\
\hline Adjusted $R^{2}$ & 0.10 & 0.13 & 0.12 & 0.09 \\
\hline Number of Countries & 174 & 168 & 174 & 185 \\
\hline Number of Observations & 5,847 & 5,225 & 5,730 & 8,836 \\
\hline \multicolumn{5}{|c|}{ B. Impact of a $1^{\circ} \mathrm{C}$ Increase in Temperature on Dependent Variable Level at Horizon 0} \\
\hline $\mathrm{AE}\left(\mathrm{T}=11^{\circ} \mathrm{C}\right)$ & $\begin{array}{l}-0.664 \\
(0.464)\end{array}$ & $\begin{array}{c}0.152 \\
(0.532)\end{array}$ & $\begin{array}{c}-0.423 \\
(0.303)\end{array}$ & $\begin{array}{c}0.547 \\
(1.077)\end{array}$ \\
\hline $\mathrm{EM}\left(\mathrm{T}=22^{\circ} \mathrm{C}\right)$ & $\begin{array}{l}-1.610^{\star * *} \\
(0.431)\end{array}$ & $\begin{array}{l}-0.977^{\star *} \\
(0.439)\end{array}$ & $\begin{array}{c}-0.578^{\star} \\
(0.298)\end{array}$ & $\begin{array}{l}-2.767^{* * *} \\
(0.664)\end{array}$ \\
\hline $\operatorname{LIDC}\left(\mathrm{T}=25^{\circ} \mathrm{C}\right)$ & $\begin{array}{l}-1.868^{\star \star *} \\
(0.517)\end{array}$ & $\begin{array}{l}-1.285^{\star *} \\
(0.538)\end{array}$ & $\begin{array}{c}-0.621^{*} \\
(0.362)\end{array}$ & $\begin{array}{l}-3.671^{* \star *} \\
(0.820)\end{array}$ \\
\hline \multicolumn{5}{|c|}{ Impact of a $1^{\circ} \mathrm{C}$ Increase in Temperature on Dependent Variable Level at Horizon 7} \\
\hline $\mathrm{AE}\left(\mathrm{T}=11^{\circ} \mathrm{C}\right)$ & $\begin{array}{l}2.070^{\star * *} \\
(0.753)\end{array}$ & $\begin{array}{c}1.642 \\
(1.798)\end{array}$ & $\begin{array}{l}-0.220 \\
(1.445)\end{array}$ & $\begin{array}{l}1.177 \\
(0.889)\end{array}$ \\
\hline $\mathrm{EM}\left(\mathrm{T}=22^{\circ} \mathrm{C}\right)$ & $\begin{array}{l}-0.498 \\
(0.654)\end{array}$ & $\begin{array}{l}-0.926 \\
(0.939)\end{array}$ & $\begin{array}{c}0.054 \\
(0.734)\end{array}$ & $\begin{array}{l}-0.509 \\
(0.812)\end{array}$ \\
\hline $\operatorname{LIDC}\left(\mathrm{T}=25^{\circ} \mathrm{C}\right)$ & $\begin{array}{c}-1.198 \\
(0.769)\end{array}$ & $\begin{array}{l}-1.626 \\
(1.117)\end{array}$ & $\begin{array}{c}0.129 \\
(0.910)\end{array}$ & $\begin{array}{l}-0.969 \\
(0.985)\end{array}$ \\
\hline \multicolumn{5}{|c|}{ C. Impact of a $100 \mathrm{~mm}$ per Year Increase in Precipitation on Dependent Variable Level at Horizon 0} \\
\hline $\mathrm{AE}(\mathrm{P}=800 \mathrm{~mm}$ per year $)$ & $\begin{array}{l}0.458^{\star \star *} \\
(0.149)\end{array}$ & $\begin{array}{c}0.076 \\
(0.105)\end{array}$ & $\begin{array}{c}-0.013 \\
(0.075)\end{array}$ & $\begin{array}{l}0.835^{\star \star \star} \\
(0.223)\end{array}$ \\
\hline EM ( $P=900 \mathrm{~mm}$ per year $)$ & $\begin{array}{l}0.428^{\star * *} \\
(0.139)\end{array}$ & $\begin{array}{c}0.072 \\
(0.100)\end{array}$ & $\begin{array}{l}-0.015 \\
(0.071)\end{array}$ & $\begin{array}{l}0.778^{\text {*** }} \\
(0.210)\end{array}$ \\
\hline LIDC $(P=1,100 \mathrm{~mm}$ per year $)$ & $\begin{array}{l}0.366^{\star \star \star *} \\
(0.121)\end{array}$ & $\begin{array}{c}0.065 \\
(0.090)\end{array}$ & $\begin{array}{l}-0.018 \\
(0.063)\end{array}$ & 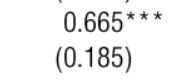 \\
\hline \multicolumn{5}{|c|}{ Impact of a $100 \mathrm{~mm}$ per Year Increase in Precipitation on Dependent Variable Level at Horizon 7} \\
\hline $\mathrm{AE}(\mathrm{P}=800 \mathrm{~mm}$ per year $)$ & $\begin{array}{c}-0.228 \\
(0.257)\end{array}$ & $\begin{array}{c}0.024 \\
(0.390)\end{array}$ & $\begin{array}{c}-0.141 \\
(0.286)\end{array}$ & $\begin{array}{l}-0.237 \\
(0.284)\end{array}$ \\
\hline EM ( $\mathrm{P}=900 \mathrm{~mm}$ per year $)$ & $\begin{array}{l}-0.213 \\
(0.243)\end{array}$ & $\begin{array}{c}0.030 \\
(0.371)\end{array}$ & $\begin{array}{l}-0.125 \\
(0.269)\end{array}$ & $\begin{array}{l}-0.217 \\
(0.267)\end{array}$ \\
\hline LIDC $(P=1,100 \mathrm{~mm}$ per year $)$ & $\begin{array}{l}-0.184 \\
(0.217)\end{array}$ & $\begin{array}{c}0.041 \\
(0.332) \\
\end{array}$ & $\begin{array}{c}-0.094 \\
(0.235) \\
\end{array}$ & $\begin{array}{l}-0.177 \\
(0.235)\end{array}$ \\
\hline
\end{tabular}

Source: IMF staff calculations.

Note: The table presents results from estimating equation (1) using the same specification as in Table 1, column (5), for different dependent variables, with separate regressions estimated for each horizon. In all specifications, standard errors are clustered at the country level. Panel A reports the estimated coefficients on the weather variables for horizon 0 . Panels $\mathrm{B}$ and $\mathrm{C}$ show the marginal impact of a change in temperature and precipitation computed as per equation (2) at the median temperature $(\mathrm{T})$ and median precipitation $(\mathrm{P})$ of advanced economies (AE), emerging markets (EM), and low-income developing countries (LIDC) contemporaneously (horizon 0 ) and cumulatively seven years after the shock. $\mathrm{mm}=$ millimeter.

${ }^{\star} p<0.1 ;{ }^{* \star} p<0.05 ;{ }^{* \star \star} p<0.01$. 
It is important to note that, unlike aggregate output, agricultural production is significantly affected by precipitation in addition to temperature shocks. Although the results suggest a concave relationship between agricultural output and precipitation, at the typical levels of precipitation of all three country groups, an increase in precipitation unambiguously improves agricultural productivity (Table 2, Panel C). The effects of precipitation are also short-lived; agricultural output seven years down the line is not affected by a precipitation shock today, which is different from the effect of temperature.

To shed light on the reasons why weather shocks affect sectors besides agriculture in such a broad and long-lasting manner, we examine how key elements of the aggregate production function - productivity, and labor and capital inputs - respond to weather shocks. As in other studies, we aim to capture the net reduced-form effects of weather on various outcomes rather than uncover the potentially complex structural relationships that may exist between these variables.

\section{Productivity}

Evidence from surveys and other sources shows that exposure to heat above a certain point reduces people's performance on both cognitive and physical tasks. ${ }^{13} \mathrm{We}$ therefore examine whether higher temperatures in parts of the world that are hot decrease labor productivity. If productivity is a channel through which weather shocks affect aggregate GDP, the effect should be significantly larger for sectors in which workers are directly exposed to the weather. We explore this hypothesis using the Groningen Growth and Development Centre 10-sector database, which provides sectoral real value added and employment in 40 countries over the period 1950-2012. We follow Graff Zivin and Neidell (2014) and classify sectors into those that are "heat-exposed" and not ${ }^{14}$ to estimate the following specification:

$$
\begin{gathered}
y_{i, s, t+h}-y_{i, s, t-1}=\beta_{1}^{h} c_{i, t}+\beta_{2}^{h} c_{i, t}^{2}+\gamma_{1}^{h} c_{i, t-1}+\gamma_{2}^{h} c_{i, t-1}^{2}+\sum_{j=1}^{h-1} \delta_{1}^{h} c_{i, t+h-j}+\sum_{j=1}^{h-1} \delta_{2}^{h} c_{i, t+h-j}^{2} \\
+\alpha_{1}^{h} c_{i, t} \times H_{s}+\alpha_{2}^{h} c_{i, t}^{2} \times H_{s}+\omega_{1}^{h} c_{i, t-1} \times H_{s}+\omega_{2}^{h} c_{i, t-1}^{2} \times H_{s}+\sum_{j=1}^{h-1} \tau_{1}^{h} c_{i, t+h-j} \times H_{s} \\
+\sum_{j=1}^{h-1} \tau_{2}^{h} c_{i, t+h-j}^{2} \times H_{s}+\varphi_{1}^{h} \Delta y_{i, s, t-1}+\mu_{i, s}^{h}+\theta_{r, t}^{h}+\varepsilon_{i, s, t}^{h},
\end{gathered}
$$

\footnotetext{
${ }^{13}$ Seppänen, Fisk, and Faulkner (2003) report a productivity loss of about 2 percent for every $1{ }^{\circ} \mathrm{C}$ increase in temperature above $25^{\circ} \mathrm{C}$, based on a survey of laboratory experiments. See also Seppänen, Fisk, and Lei (2006) for a meta-analysis of the literature, Somanathan et al. (2017) for recent evidence on labor productivity from India, and Deryugina and Hsiang (2014) for evidence from the United States. Heat stress may also reduce cognitive function as captured in student performance (Wargocki and Wyon 2007; Graff Zivin, Hsiang and Neidell 2015; Garg, Jagnani, and Taraz 2017; Park 2017).

${ }^{14}$ According to Graff Zivin and Neidell (2014), who follow definitions from the National Institute for Occupational Safety and Health, heat-exposed industries include agriculture, forestry, fishing, and hunting; construction; mining; transportation; and utilities - as well as manufacturing in which facilities may not be climate-controlled in low-income countries and production processes often generate considerable heat.
} 
in which $y_{i, s, t}$ is the log of real sectoral value added per worker, $H_{S}$ is an indicator for sectors that are "heat-exposed," $\mu_{i, s}^{h}$ are country-sector fixed effects, and $\theta_{r, t}^{h}$ are region-year fixed effects. Standard errors are clustered at the country level.

Specification (5) in Table 3 summarizes the results of this estimation. Panel A contains the estimated coefficients on temperature and precipitation and their squared terms for non-heat-exposed sectors $\left(\beta_{1}^{h}, \beta_{2}^{h}\right)$ and heat-exposed sectors $\left(\beta_{1}^{h}+\right.$ $\alpha_{1}^{h}, \beta_{2}^{h}+\alpha_{2}^{h}$ ). Panels B and C present the estimated impacts of temperature and precipitation evaluated for the median advanced, emerging market and low-income country in the year of the shock, as well as seven years later. Panels 1 and 2 in Figure 9 plot the impulse response function of real output per worker to a $1^{\circ} \mathrm{C}$ increase in temperature for heat-exposed and non-heatexposed sectors evaluated at the average annual temperature of the median lowincome country.

Our analysis suggests that at higher temperatures, an increase in temperature significantly lowers labor productivity in heat-exposed industries. Temperature increases, however, have no discernible effect on the productivity of workers in nonheat-exposed sectors, even in countries with hot climates. Of course, productivity may decline if weather shocks provoke political instability, incite conflict, or undermine governing institutions in other ways, as discussed in numerous studies that document a strong link between weather shocks and these outcomes. $^{15}$
Figure 9. Effect of Temperature Increase on Productivity, Capital, and Labor Input Estimated at the Temperature of the Median Low-Income Developing Country (Percent; years on $\mathrm{x}$-axis)

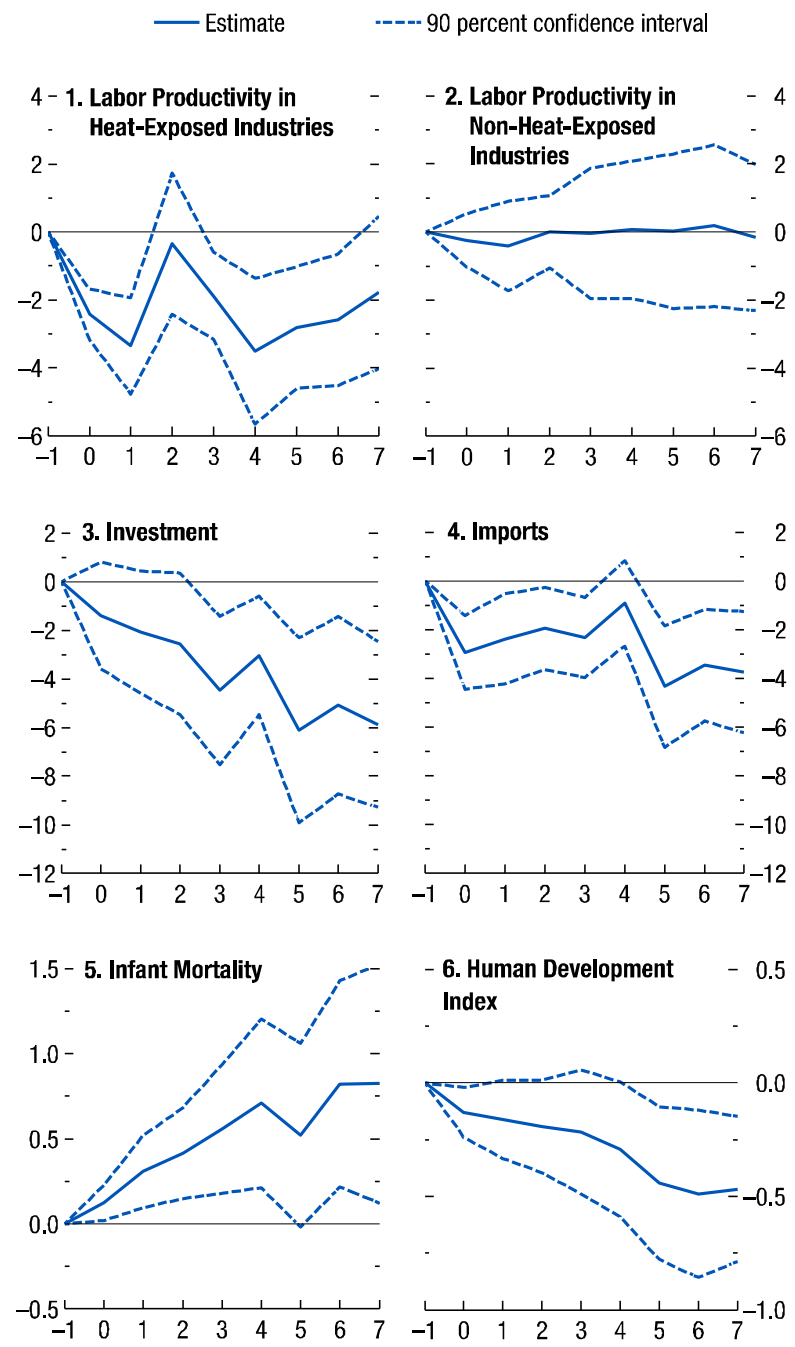

Source: IMF staff calculations.

Note: The panels depict the effect of a $1^{\circ} \mathrm{C}$ increase in temperature estimated at the median low-income developing country temperature $\left(25^{\circ} \mathrm{C}\right)$. Horizon 0 is the year of the shock. Heat-exposed industries include agriculture, forestry, fishing and hunting, construction, mining, transportation, utilities, and manufacturing, following Graff Zivin and Neidell (2014).

\footnotetext{
${ }^{15}$ Burke, Hsiang, and Miguel (2015b) review the literature that links climate to conflict. Forcible removal of rulers has also been linked to fluctuations in climate (Dell, Jones, and Olken 2012; Kim 2014; Burke and Leigh 2010; Chaney 2013), and several historical cases of societal collapse have been compellingly attributed to climate change (Cullen et al. 2000; Haug et al. 2003; Buckley et al. 2010; Büntgen et al. 2011).
} 
Table 3. Effect of Weather Shocks on Productivity, Capital, and Labor

\begin{tabular}{|c|c|c|c|c|c|c|}
\hline \multirow[b]{2}{*}{ A. Dependent Variable } & \multicolumn{2}{|c|}{ Capital Input } & \multicolumn{2}{|c|}{ Labor Input } & \multicolumn{2}{|c|}{ Labor Productivity } \\
\hline & $\begin{array}{c}\text { Investment } \\
\text { (1) }\end{array}$ & $\begin{array}{c}\text { Imports } \\
(2)\end{array}$ & $\begin{array}{c}\text { Infant } \\
\text { Mortality } \\
(3)\end{array}$ & $\begin{array}{l}\mathrm{HDI} \\
(4)\end{array}$ & $\begin{array}{c}\text { Non-Heat } \\
\text { Exposed }\end{array}$ & $\begin{array}{c}\text { Heat } \\
\text { Exposed }\end{array}$ \\
\hline \multirow[t]{2}{*}{ Temperature } & 0.850 & 0.467 & -0.147 & $0.269^{\star \star \star}$ & 0.246 & $1.902^{\star}$ \\
\hline & (2.042) & $(0.943)$ & $(0.117)$ & $(0.078)$ & $(0.681)$ & $(1.002)$ \\
\hline \multirow[t]{2}{*}{ Temperature $^{2}$} & -0.045 & $-0.068^{* *}$ & $0.005^{\star}$ & $-0.008^{\star \star *}$ & -0.010 & $-0.087^{\star * *}$ \\
\hline & $(0.059)$ & $(0.033)$ & $(0.003)$ & $(0.002)$ & $(0.018)$ & $(0.026)$ \\
\hline \multirow[t]{2}{*}{ Precipitation } & -0.377 & $-0.654^{\star *}$ & -0.001 & 0.000 & 0.047 & 0.272 \\
\hline & $(0.398)$ & $(0.271)$ & $(0.024)$ & $(0.018)$ & $(0.201)$ & $(0.195)$ \\
\hline \multirow[t]{2}{*}{ Precipitation ${ }^{2}$} & 0.003 & 0.006 & 0.001 & -0.000 & -0.003 & $-0.008^{*}$ \\
\hline & $(0.009)$ & $(0.007)$ & $(0.001)$ & $(0.000)$ & $(0.005)$ & $(0.004)$ \\
\hline Adjusted $R^{2}$ & 0.03 & 0.08 & 0.64 & 0.31 & \multicolumn{2}{|c|}{0.03} \\
\hline Number of Countries & 169 & 178 & 182 & 181 & \multicolumn{2}{|c|}{40} \\
\hline Number of Observations & 6,093 & 6,866 & 8,685 & 3,864 & \multicolumn{2}{|c|}{17,848} \\
\hline \multicolumn{7}{|c|}{ B. Impact of a $1^{\circ} \mathrm{C}$ Increase in Temperature on Dependent Variable Level at Horizon 0} \\
\hline \multirow[t]{2}{*}{$\mathrm{AE}\left(\mathrm{T}=11^{\circ} \mathrm{C}\right)$} & -0.138 & $-1.029^{\star \star \star}$ & -0.028 & $0.094^{\star *}$ & 0.030 & -0.003 \\
\hline & $(0.976)$ & $(0.455)$ & $(0.067)$ & $(0.043)$ & $(0.396)$ & $(0.502)$ \\
\hline \multirow[t]{2}{*}{$\mathrm{EM}\left(\mathrm{T}=22^{\circ} \mathrm{C}\right)$} & -1.126 & $-2.525^{\star \star *}$ & $0.092^{*}$ & -0.082 & -0.185 & $-1.909 * * *$ \\
\hline & $(1.064)$ & $(0.753)$ & $(0.055)$ & $(0.056)$ & $(0.412)$ & $(0.363)$ \\
\hline \multirow[t]{2}{*}{$\operatorname{LIDC}\left(\mathrm{T}=25^{\circ} \mathrm{C}\right)$} & -1.395 & $-2.934^{* * *}$ & $0.124^{*}$ & $-0.129^{*}$ & -0.244 & $-2.428^{\star * *}$ \\
\hline & $(1.331)$ & $(0.919)$ & $(0.063)$ & $(0.067)$ & $(0.478)$ & $(0.456)$ \\
\hline \multicolumn{7}{|c|}{ Impact of a $1^{\circ} \mathrm{C}$ Increase in Temperature on Dependent Variable Level at Horizon 7} \\
\hline \multirow[t]{2}{*}{$\mathrm{AE}\left(\mathrm{T}=11^{\circ} \mathrm{C}\right)$} & 1.812 & 2.361 & -0.364 & $0.609^{\star \star}$ & 0.305 & -1.142 \\
\hline & (2.029) & (1.494) & $(0.427)$ & $(0.259)$ & (1.183) & (0.986) \\
\hline \multirow[t]{2}{*}{$\mathrm{EM}\left(\mathrm{T}=22^{\circ} \mathrm{C}\right)$} & $-4.225^{\star \star}$ & $-2.439^{\star}$ & 0.569 & -0.237 & -0.063 & -1.642 \\
\hline & $(1.803)$ & (1.303) & $(0.375)$ & $(0.175)$ & $(1.114)$ & (1.119) \\
\hline \multirow[t]{2}{*}{$\operatorname{LIDC}\left(\mathrm{T}=25^{\circ} \mathrm{C}\right)$} & $-5.871^{\star \star \star}$ & $-3.747^{\star \star}$ & $0.824^{\star}$ & $-0.467^{\star \star}$ & -0.163 & -1.778 \\
\hline & $(2.074)$ & $(1.516)$ & $(0.426)$ & $(0.195)$ & $(1.306)$ & $(1.365)$ \\
\hline \multicolumn{7}{|c|}{ C. Impact of a $100 \mathrm{~mm}$ per Year Increase in Precipitation on Dependent Variable Level at Horizon 0} \\
\hline \multirow[t]{2}{*}{$\mathrm{AE}(\mathrm{P}=800 \mathrm{~mm}$ per year $)$} & -0.329 & $-0.558^{\star \star \star *}$ & 0.008 & -0.007 & -0.009 & 0.148 \\
\hline & $(0.262)$ & $(0.180)$ & $(0.015)$ & $(0.013)$ & $(0.133)$ & $(0.136)$ \\
\hline \multirow[t]{2}{*}{ EM $(P=900 \mathrm{~mm}$ per year $)$} & -0.323 & $-0.547^{\star * \star}$ & 0.009 & -0.008 & -0.016 & 0.132 \\
\hline & $(0.246)$ & $(0.170)$ & $(0.015)$ & $(0.012)$ & $(0.125)$ & $(0.130)$ \\
\hline \multirow[t]{2}{*}{ LIDC ( $\mathrm{P}=1,100 \mathrm{~mm}$ per year $)$} & -0.311 & $-0.523^{\star \star \star}$ & 0.011 & -0.010 & -0.030 & 0.101 \\
\hline & $(0.216)$ & $(0.151)$ & $(0.013)$ & $(0.011)$ & $(0.109)$ & $(0.118)$ \\
\hline \multicolumn{7}{|c|}{ Impact of a $100 \mathrm{~mm}$ per Year Increase in Precipitation on Dependent Variable Level at Horizon 7} \\
\hline $\mathrm{AE}(\mathrm{P}=800 \mathrm{~mm}$ per year $)$ & -0.478 & $-0.984^{\star *}$ & 0.071 & $-0.102^{\star}$ & -0.295 & 0.072 \\
\hline & $(0.689)$ & $(0.498)$ & $(0.163)$ & $(0.061)$ & $(0.832)$ & $(0.554)$ \\
\hline $\mathrm{EM}(\mathrm{P}=900 \mathrm{~mm}$ per year $)$ & -0.423 & $-0.961^{\star \star}$ & 0.074 & $-0.097^{\star}$ & -0.265 & 0.041 \\
\hline & $(0.649)$ & $(0.472)$ & $(0.149)$ & $(0.057)$ & $(0.776)$ & $(0.524)$ \\
\hline LIDC ( $P=1,100 \mathrm{~mm}$ per year $)$ & -0.313 & $-0.914^{\star \star}$ & 0.080 & $-0.087^{\star}$ & -0.206 & -0.022 \\
\hline & $(0.573)$ & $(0.422)$ & $(0.123)$ & $(0.050)$ & $(0.666)$ & $(0.467)$ \\
\hline
\end{tabular}

Source: IMF staff calculations.

Note: Columns (1-4) present results from estimating equation (1) using the same specification as in Table 1, column (5), for different dependent variables. Specification in column (5) presents results from estimating equation (3) where an indicator for heat exposed sectors is interacted with temperature and precipitation, their squared terms, and their lags and forwards; also controlling for country-sector and region-year fixed effects, and lag of growth. Separate regressions are estimated for each horizon. In all specifications, standard errors are clustered at the country level. Panel A reports the estimated coefficients on the weather variables for horizon 0 . Panels $B$ and $\mathrm{C}$ show the marginal impact of a change in temperature and precipitation computed as per equation (2) at the median temperature $(\mathrm{T})$ and median precipitation $(\mathrm{P})$ of advanced economies (AE), emerging markets $(\mathrm{EM})$, and low-income developing countries (LIDC), contemporaneously (horizon 0 ) and cumulatively seven years after the shock. HDI = Human Development Index; $\mathrm{mm}=$ millimeter.

${ }^{\star} p<0.1 ;{ }^{\star \star} p<0.05 ;{ }^{\star \star \star} p<0.01$.

\section{CInternational Monetary Fund. Not for Redistribution}




\section{Capital Accumulation}

Temperature increases are largely supply-side shocks, but they could lead to persistent output losses and affect growth if they influence the rate of factor accumulation. Investment may fall in response to temperature shocks because there are fewer resources to invest, because the rate of return on capital is lower and/or because the temporary negative shock to income raises the cost of financing investment in an environment of imperfect capital markets (see, for example, Fankhauser and Tol 2005). When access to formal savings, credit, or insurance is limited, households may also sell productive assets to smooth consumption in response to weather shocks.

Using national accounts data, we examine the response of the main components of aggregate demand - gross capital formation, consumption, exports, and imports - to weather shocks using the empirical framework given by equation (1). At the temperature of the median low-income country, all four components respond negatively to a $1^{\circ} \mathrm{C}$ increase in temperature, although the uncertainty surrounding the estimated contemporaneous effects is large. However, in the medium term, the effect is most pronounced for investment (Table 3, column 1). Seven years after the shock, investment is estimated to be 6 percent lower than it would have been in the absence of the shock as depicted in Figure 9, panel 3. Imports, which are typically closely tied to investment, also exhibit a significant and long-lasting drop as temperature rises (Table 3, column 2 and Figure 9, panel 4).

The negative effect of temperature shocks on aggregate investment is consistent with evidence from household-level studies, which find that weather shocks could slow or even reverse capital accumulation as households try to smooth consumption or perceive investment as too risky (Hallegatte et al. 2016).

\section{Labor Supply}

Finally, we examine whether labor supply may be affected by weather fluctuations, for example, through their effect on health. In the absence of comprehensive and comparable data on adult health outcomes, we focus on infant mortality as an imperfect proxy. Estimating equation (1) with infant mortality as dependent variable reveals that, in hot climates, higher temperatures may reduce (future) labor supply because of their influence on mortality rates (Table 3, column 3 and Figure 9, panel 5). A $1^{\circ} \mathrm{C}$ increase in temperature raises infant mortality by 0.12 percentage point in the year of the shock. The effect grows through the estimation period as weather-related lower income (and potential food insecurity) reinforces the direct physiological impact of higher temperatures in hot climates.

This cross-country panel evidence corroborates findings in numerous studies of links between weather and mortality, prenatal health, and other health outcomes in different countries. Deschênes (2012) and Guo et al. (2014) provide comprehensive reviews of the literature on the link between temperature and mortality and health from a large number of 
countries. ${ }^{16}$ Graff Zivin and Neidell (2014), Deryugina and Hsiang (2014), Park (2017), and Somanathan et al. (2017) find a direct effect of higher temperature on labor supply and productivity. The adverse effects on the health and educational attainment of children could be one of the key reasons behind the long-lasting nature of weather's consequences. Indeed, we find that higher temperatures also have a negative effect on a broader measure of human well-being, the Human Development Index, a weighted average of per capita income, educational achievement, and life expectancy as documented in Table 3, column 4 and Figure 9, panel 6.

\section{LONG-TERM EFFECTS OF TEMPERATURE INCREASE-A MODEL-BASED APPROACH}

Our empirical work assessed the macroeconomic effects of weather shocks in the short and medium term. We incorporate these estimates into a dynamic general equilibrium model to shed light on the potential long-term effects of temperature increases on GDP, investment, and public debt for a representative small open low-income economy. The model also highlights the role that structural transformation of low-income countries (that is, the transition from agriculture to a more services-based economy) could play in attenuating the impact of climate change.

Our simulations are based on the Debt, Investment and Growth (DIG) model of Buffie et al. (2012), which captures various aspects pertinent to low-income countries - such as low public investment efficiency and high capital adjustment costs - and can be extended easily to incorporate the structural transformation process. ${ }^{17}$ These aspects of the DIG model make it preferable for studying the impact of climate change in low-income countries relative to the IAMs more commonly used to assess climate change effects.

In the DIG model, firms combine labor, private capital, and infrastructure to produce output. Consumers supply labor and derive utility from consuming traded and nontraded goods, while the government collects revenue, redistributes income, and invests in infrastructure, which it funds through domestic and external borrowing, grants, and remittances. Based on the empirical results, we model changes in the exogenously given sector-specific total factor productivity levels as quadratic functions of temperature, while we calibrate all other parameters broadly as in Buffie et al. (2012). In particular, $T F P_{t+1}-$ $T F P_{t}=\beta_{1}^{1}\left(T_{t+1}-T_{t}\right)+2 \beta_{2}^{1}\left(T_{t+1}-T_{t}\right) T_{t}+\Delta T F P_{t}^{*}$, in which $\Delta T F P_{t}^{*}$ is the total factor productivity growth rate that would prevail under no climate change, assumed to be 2.8 percent based on the World Economic Outlook medium-term growth forecast for low-income countries. $\beta_{1,1}$ and $\beta_{1,2}$ are the estimated coefficients on the linear and squared temperature

\footnotetext{
${ }^{16}$ See also Burgess et al. (2014) for evidence from India; Kudamatsu, Persson, and Strömberg (2012) for evidence from a subset of African countries; and Barreca (2012); Barreca et al. (2016); and Deschênes and Greenstone (2011) for evidence from the United States.

${ }^{17}$ For a detailed description of the model, see Buffie et al. (2012) and Annex 2.
} 
terms in equation (1), as reported in column (5) of Table 1, rescaled to match the modeled decline of GDP when temperature increases by $1^{\circ} \mathrm{C}$, and $T_{t}$ is the average annual temperature for the median lowincome country at time $t$, where the initial temperature is set at $25^{\circ} \mathrm{C}$.

We examine the effects of climate change by simulating the macroeconomic response of output, the public-debt-to-GDP ratio, and private investment to the temperature increases projected under two of the scenarios prepared by the IPCC, as discussed in Section II. The simulations suggest that under both scenarios, the representative lowincome country will experience sizable economic losses relative to a baseline of no changes in temperature, with significant downside risks (Figure 10).

In the milder scenario, the increase in temperature will lower output by 4 percent by 2100 and depress private investment by 5 percent as firms respond to lower productivity from rising temperatures by cutting back capital spending. The relative decline in output implies an increase in the public-debt-to-GDP ratio of 2 percentage points by 2100 . In the unmitigated climate change scenario, the macroeconomic effect would be much larger. Output would fall by close to 9 percent relative to no climate change, private investment would fall by 11 percent, and the public-debt-to-GDP ratio would rise by 5 percentage points by 2100 . These

Figure 10. Long-Term Impact of Temperature Increase for a Representative Low-Income Developing Country: Model Simulations
Intermediate Scenario (RCP 4.5)
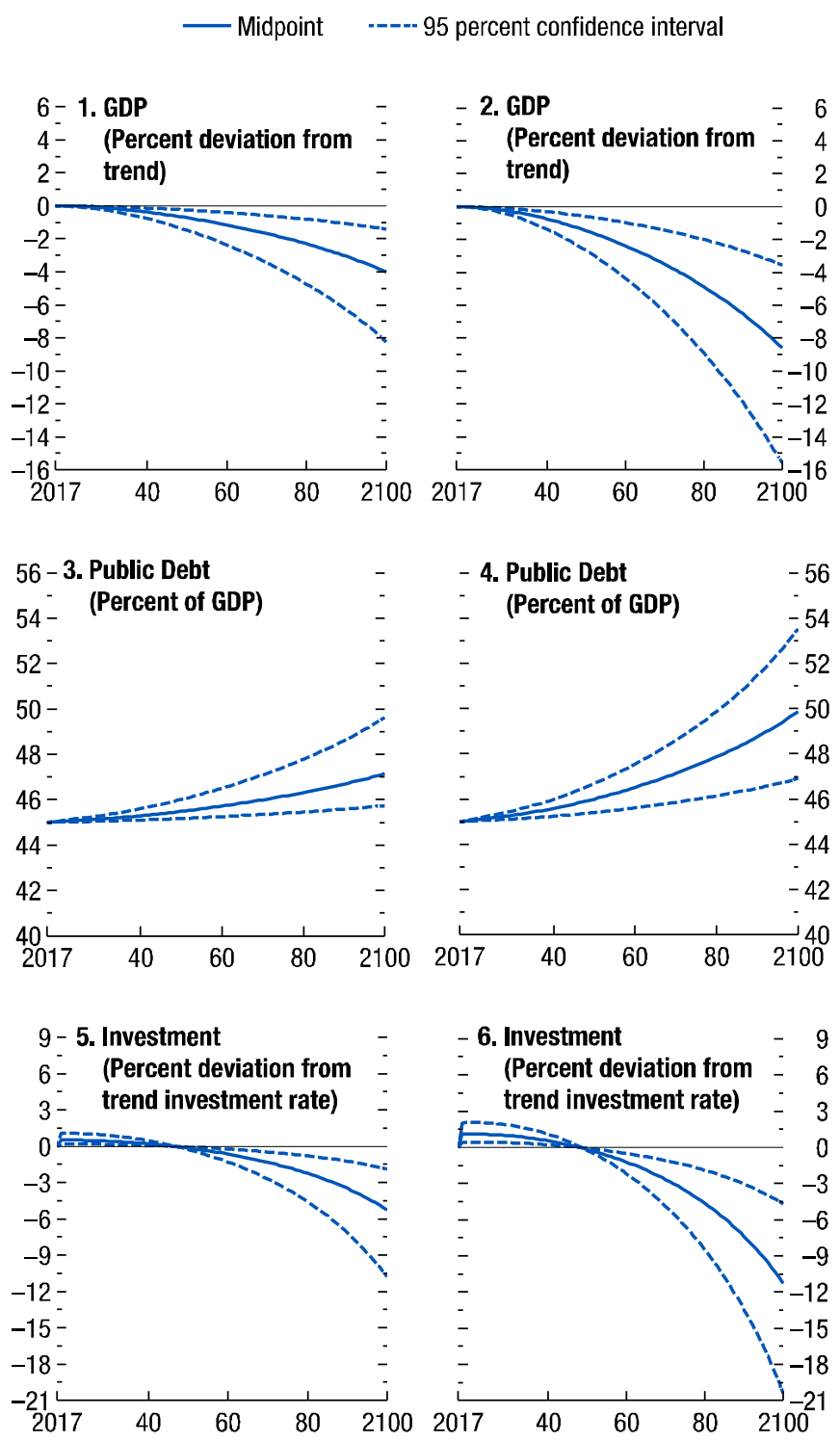

Source: IMF staff calculations Note: RCP $=$ Representative Concentration Pathways.
Unmitigated Climate Change Scenario (RCP 8.5) 
results are broadly in line with other model-based estimates of the impact of climate change as discussed in Tol (2009). ${ }^{18}$

There is great uncertainty surrounding these central projections because empirical estimates of the effect of temperature shocks are imprecise and temperature projections are uncertain. We combine these sources of uncertainty as follows. The upper-bound scenario is simulated assuming that the temperature increase is equal to the lowest 5 th percentile for each RCP. ${ }^{19}$ To account for the uncertainty of estimated parameters, the TFP parameters are set to the conditional expected value for the upper 50 percent of the TFP distribution. The worst lower-bound scenario is simulated analogously.

As a result of these uncertainties, wide confidence intervals surround our central projections. There is a 2.5 percent chance of output declining more than 8 percent below the trend in the milder scenario and more than 16 percent in the unmitigated climate change scenario. In line with lower output, public debt would increase significantly relative to output (about 10 percent of GDP in the worst-case scenario), and the private-investment-to-GDP ratio could plummet by as much as 20 percent below the trend.

An alternative way to quantify climate change damage for a representative lowincome country is to compute the present value of the shortfall in economic output relative to the baseline of no climate change and to express this present value as a share of current output. ${ }^{20}$ Using a moderate growth-adjusted discount rate of 1.4 percent, the present value of output losses is large, at 48 percent and 100 percent of current output under the RCP 4.5 and RCP 8.5 scenarios, respectively.

The above simulations assume a static economic structure. However, as discussed in Section V, rising temperatures affect some economic sectors more than others. For example, compared with agriculture, the services sector is relatively sheltered from the adverse effects of higher temperature. Hence, structural economic transformation from a mostly agrarian to a more services-based economy could lower the economic cost of climate change. We extend the baseline DIG model to include an exogenous process of reallocating labor from agriculture and manufacturing to services. The pace of structural transformation is assumed to be moderate and replicates past trends for low-income countries: in the absence of shocks, the employment share of the services sector rises by 2.5 percentage points a decade. Simulations in this extended model indicate that over the long term, for the median low-

\footnotetext{
${ }^{18}$ For a survey of estimates of climate change damage at the global level, see Tol (2014) and Nordhaus and Moffat (2017).

${ }^{19}$ Here, the 5-95 percent confidence intervals for the temperature increases are $1.2^{\circ} \mathrm{C}$ to $2.8^{\circ} \mathrm{C}$ and $2.8^{\circ} \mathrm{C}$ to $5.1^{\circ} \mathrm{C}$ for RCP 4.5 and RCP 8.5 , respectively.

${ }^{20}$ In line with Nordhaus (2016), the real interest rate is assumed to be 4.25 percent, giving a growth-adjusted discount rate of 1.4 percent. A more extreme discount rate of 0.1 percent, proposed by Stern (2007), would increase the present value of damage by an order of magnitude.
} 
income country, structural transformation can reduce the cost of climate change by about 25 and 30 percent in the RCP 4.5 and RCP 8.5 scenarios, respectively.

The potential impact of climate change quantified in this section is subject to important caveats. First, extrapolating from the short- to medium-term causal effects of weather shocks estimated from historical data to the long-term impact of potential global warming may overstate the case if persistent changes in climate induce agents to adapt their economic activity to the new environment. Conversely, permanent changes in climate may have consequences that fluctuations in annual weather do not. Moreover, the model does not capture the effects of extreme weather events, which inflict long-lasting macroeconomic damage, and could increase in frequency, potentially amplifying the damage they cause. Certain expected or possible events (such as rising sea levels) have no historic precedents from which to draw inference but may have very significant economic consequences for many low-income countries, which are also not quantified in our simulations. Moreover, the long-term projections do not incorporate several of the channels through which temperature increases, and climate change in general, could affect economic activity, such as declining labor supply from higher mortality and migration.

Even abstracting from these difficulties, considerable uncertainty exists about how to incorporate the empirical estimates of economic losses into the dynamic general equilibrium model. We have taken a very conservative approach and assume that weather shocks have a permanent effect on the level of output. However, several studies have argued that the empirical evidence is not inconsistent with a persistent effect on the growth rate of output (Dell, Jones, and Olken 2012; Burke, Hsiang, and Miguel 2015a). Permanent growth effects could arise if weather shocks scar productivity growth through their effects on institutions, innovation, or human capital accumulation. Since even a small growth effect would ultimately dwarf a level effect, the adverse consequence of temperature increases for the median low-income country would be many times larger if rising temperatures were incorporated into the model as affecting the growth path of output, as done by Burke, Hsiang and Miguel (2015a).

\section{Summary And Policy Implications}

Coping with climate change is one of the fundamental challenges of the $21^{\text {st }}$ century, and this challenge looms particularly large for low-income economies. We document the extraordinarily fast rise in temperature over the past century across advanced, emerging market, and low-income economies. Low-income countries, which tend to be in some of the hottest parts of the planet and are projected to experience sizable increases in temperature depending on our ability to contain future GHG emissions, have contributed very little to the atmospheric concentration of GHGs.

The analysis suggests that rising temperatures have highly uneven macroeconomic effects, with the adverse consequences borne disproportionately by countries with hot 
climates, such as most low-income countries. We find that a rise in temperature lowers per capita output in countries with high average temperatures, in both the short and medium term, through a wide array of channels. In areas with hot climates, higher temperatures reduce agricultural output, lower productivity of workers exposed to the heat, slow the rate of capital accumulation, and damage health. These findings reflect impacts of weather shocks on average country outcomes. But weather shocks could also have sizable unfavorable distributional consequences within a country. Poor households tend to be more vulnerable to weather fluctuations as a result of their heavy reliance on agricultural income, higher proportion of income devoted to food items, and limited access to savings and credit (Hallegatte et al. 2016; Hallegatte and Rozenberg 2017; IMF 2016b).

The negative effects of projected climate change for low-income countries could be large. Focusing on one particular aspect of climate change - namely, projected rise in temperature - and under the conservative assumption that temperature increases affect the level, rather than growth path, of output, model simulations suggest that absent efforts to reduce global emissions, the output of a representative low-income country could be 9 percent lower than without an increase in temperature. Moreover, the negative welfare consequences of changing climate conditions will likely exceed output losses.

Uncomfortably high temperatures may spur investment as households adapt, but the increase in economic activity may not be welfare-enhancing. The significant uncertainty about the magnitude and effects of climate change — not only how much temperatures will rise but also how the environment will react — calls for careful consideration of the sizable downside risks that surround our projections.

While our analysis emphasized the impact of global warming on low-income countries, it is important to note that all countries will increasingly feel direct negative effects from unmitigated climate change, through more frequent (and damaging) natural disasters, rising sea level, loss of biodiversity and many other difficult-to-quantify consequences. Warming will also begin to weigh on growth in many advanced economies, as their temperatures rise above optimal levels. By combining the estimated sensitivity of per capita output to temperature increase, baseline annual temperatures and projected temperature increase under the two RCP scenarios, Figure 11 depicts the potential cumulative impacts on 2100 per capita GDP across the globe. This exercise confirms the highly uneven effects of warming across the glove, but also reveals that the projected increase in temperature, especially under the RCP 8.5 scenario, will push many advanced economies beyond the threshold temperature levels, thus triggering direct economic losses for these countries as well. And even in countries where the effect might be moderate or positive on average, climate change will create winners and losers at both the individual and sectoral levels. Moreover, the international spillovers from the most vulnerable countries, through depressed economic activity and potentially higher conflict and migration flows, could be considerable. Going forward, only a global effort to contain carbon emissions to levels consistent with an acceptable increase in temperature can limit the long-term risks of climate change (Farid et al. 2016; Hallegatte et al. 2016; IMF 2015; Stern 2015; IPCC 2014). 
Figure 11. The Long-Term Impact of Temperature Increase on Real per Capita Output across the Globe (Percent)
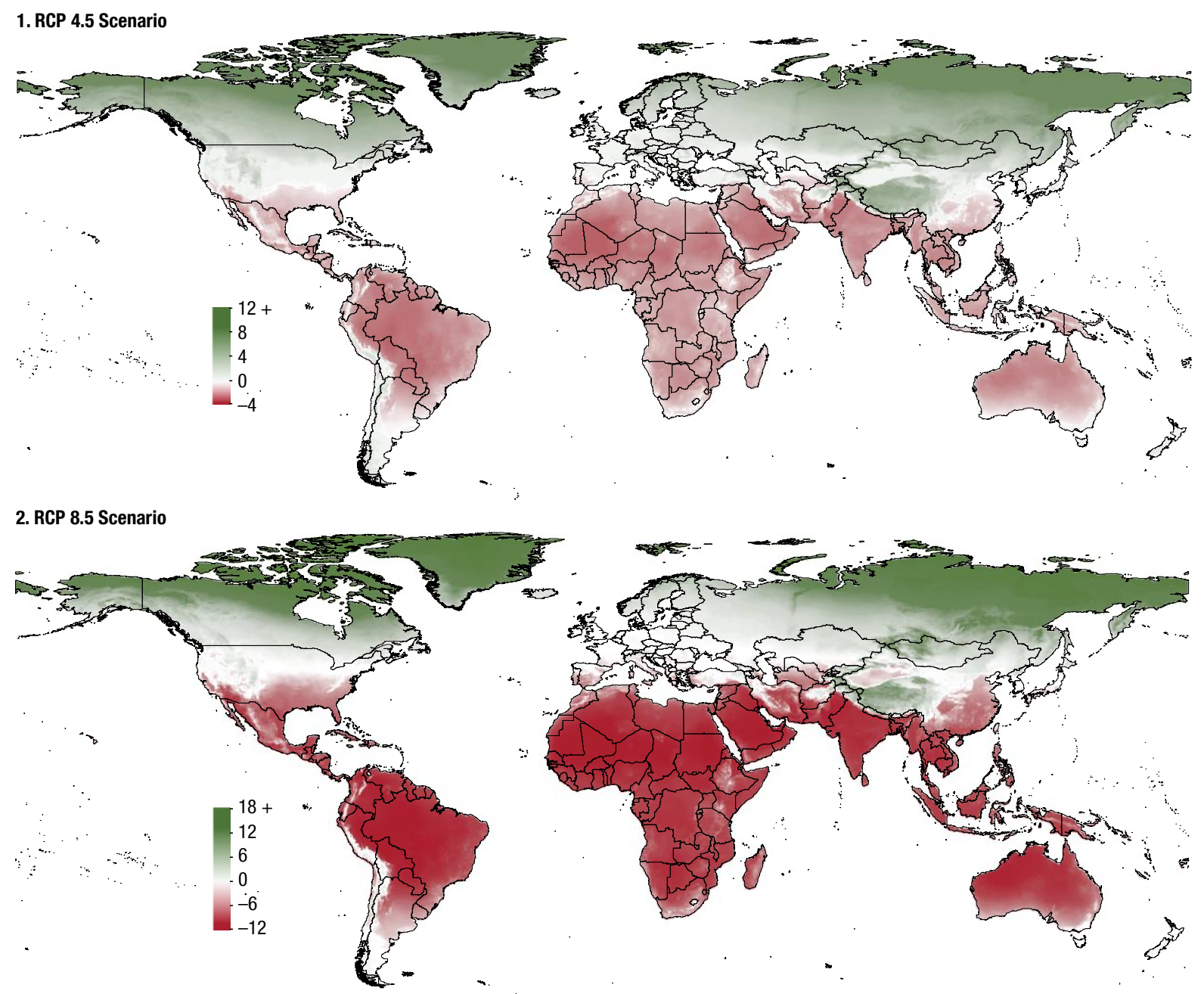

Sources: National Aeronautics and Space Administration (NASA) Earth Exchange Global Daily Downscaled Projections (NEX-GDDP); World Bank Group Cartography Unit; and IMF staff calculations.

Note: The maps depict the effect of the projected increase in temperature between 2005 and 2100 under RCP 4.5 and RCP 8.5 scenarios on real per capita output in 2100. Gray areas indicate the estimated impact is not statistically significant RCP $=$ Representative Concentration Pathways. 


\section{AnNeX 1. Data Sources AND Country Groupings}

\begin{tabular}{|c|c|}
\hline Indicator & Source \\
\hline Temperature, Historical & $\begin{array}{l}\text { Intergovernmental Panel on Climate Change (IPCC) Coupled Model Intercomparison Project Phase Five AR5 } \\
\text { Atlas subset; Marcott and others (2013); Matsuura and Willmott (2007); National Aeronautics and Space } \\
\text { Administration (NASA) Goddard Institute for Space Studies (GISS); Royal Netherlands Meteorological } \\
\text { Institute (KNMI) Climate Change Atlas; Shakun and others (2012) }\end{array}$ \\
\hline $\begin{array}{l}\text { Temperature and Precipitation, } \\
\text { Forecast (Grid level) }\end{array}$ & NASA Earth Exchange Global Daily Downscaled Projections data set (NEX-GDDP) \\
\hline $\begin{array}{l}\text { Temperature and Precipitation, } \\
\text { Historical (Grid level) }\end{array}$ & University of East Anglia, Climate Research Unit (CRU TS v.3.24); University of Delaware (UDEL v.4.01) \\
\hline $\begin{array}{l}\text { Population 2010, 1990, } 1950 \\
\text { (Grid level) }\end{array}$ & $\begin{array}{l}\text { Center for International Earth Science Information Network (CIESIN v.3 and v.4); History Database of the } \\
\text { Global Environment (HYDE v3.2); Klein and others (2016) }\end{array}$ \\
\hline $\begin{array}{l}\text { Population } 2015 \text { and Projected Population } \\
2100\end{array}$ & United Nations World Population Prospects database, 2015 Revision \\
\hline $\mathrm{CO}_{2}$ Emissions & Carbon Dioxide Information Analysis Center \\
\hline Temperature Forcings & Carbon Dioxide Information Analysis Center; NASA GISS; Roston and Migliozzi (2015) \\
\hline Real GDP per Capita & IMF, World Economic Outlook database; World Bank, World Development Indicators database \\
\hline Crop Production Index & Food and Agriculture Organization; World Bank, World Development Indicators database \\
\hline $\begin{array}{l}\text { Sectoral Real Value Added } \\
\text { (Agriculture, manufacturing, services) }\end{array}$ & World Bank, World Development Indicators database \\
\hline Sectoral Labor Productivity & Groningen Growth and Development Centre 10-Sector Database; Timmer, de Vries, and de Vries (2015) \\
\hline Real Gross Capital Formation & IMF, World Economic Outlook database; World Bank, World Development Indicators database \\
\hline Real Imports of Goods and Services & IMF, World Economic Outlook database; World Bank, World Development Indicators database \\
\hline Infant Mortality Rate & World Bank, World Development Indicators database \\
\hline Human Development Index & United Nations Development Programme, Human Development Report database \\
\hline
\end{tabular}

Source: IMF staff compilation.

\section{Annex Table 1.2. Country and Territory Groups}

\begin{tabular}{|c|c|}
\hline $\begin{array}{l}\text { Advanced } \\
\text { Economies }\end{array}$ & $\begin{array}{l}\text { Australia, Austria, Belgium, Canada, Cyprus, Czech Republic, Denmark, Estonia, Finland, France, Germany, Greece, Hong Kong SAR, }{ }^{*} \\
\text { Iceland, Ireland, Israel, Italy, Japan, Korea, Latvia, Lithuania, Luxembourg, Macao SAR, }{ }^{\star} \text { Malta, Netherlands, New Zealand, Norway, } \\
\text { Portugal, Puerto Rico, San Marino, }{ }^{*} \text { Singapore, Slovak Republic, Slovenia, Spain, Sweden, Switzerland, Taiwan Province of China, }{ }^{*} \\
\text { United Kingdom, United States }\end{array}$ \\
\hline $\begin{array}{l}\text { Emerging Market } \\
\text { Economies }\end{array}$ & $\begin{array}{l}\text { Albania, Algeria, Angola, Antigua and Barbuda, Argentina, Armenia, Azerbaijan, The Bahamas, }{ }^{*} \text { Bahrain, Barbados, Belarus, Belize, Bosnia } \\
\text { and Herzegovina, Botswana, Brazil, Brunei Darussalam, Bulgaria, Cabo Verde, Chile, China, Colombia, Costa Rica, Croatia, Dominica, } \\
\text { Dominican Republic, Ecuador, Egypt, El Salvador, Equatorial Guinea, Fiji, Gabon, Georgia, Grenada, Guatemala, Guyana, Hungary, India, } \\
\text { Indonesia, Iran, Iraq, Jamaica, Jordan, Kazakhstan, Kosovo, }{ }^{\star} \text { Kuwait, Lebanon, Libya, Macedonia FYR, Malaysia, Maldives, }{ }^{*} \text { Marshall } \\
\text { Islands, }{ }^{*} \text { Mauritius, Mexico, Micronesia, }{ }^{*} \text { Montenegro, Morocco, Namibia, Nauru, }{ }^{*} \text { Oman, Pakistan, Palau, }{ }^{*} \text { Panama, Paraguay, Peru, } \\
\text { Philippines, Poland, Qatar, Romania, Russia, Samoa, Saudi Arabia, Serbia, Seychelles, }{ }^{*} \text { South Africa, Sri Lanka, St. Kitts and Nevis, St. } \\
\text { Lucia, St. Vincent and the Grenadines, Suriname, Swaziland, Syria, Thailand, Timor-Leste, Tonga, Trinidad and Tobago, Tunisia, Turkey, } \\
\text { Turkmenistan, Tuvalu, }{ }^{*} \text { Ukraine, United Arab Emirates, Uruguay, Vanuatu, Venezuela }\end{array}$ \\
\hline $\begin{array}{l}\text { Low-Income } \\
\text { Developing } \\
\text { Countries }\end{array}$ & $\begin{array}{l}\text { Afghanistan, Bangladesh, Benin, Bhutan, Bolivia, Burkina Faso, Burundi, Cambodia, Cameroon, Central African Republic, Chad, Comoros, } \\
\text { Democratic Republic of the Congo, Republic of Congo, Côte d’Ivoire, Djibouti, Eritrea, Ethiopia, The Gambia, Ghana, Guinea, Guinea-Bissau, } \\
\text { Haiti, Honduras, Kenya, Kiribati, * Kyrgyz Republic, Lao P.D.R., Lesotho, Liberia, Madagascar, Malawi, Mali, Mauritania, Moldova, Mongolia, } \\
\text { Mozambique, Myanmar, Nepal, Nicaragua, Niger, Nigeria, Papua New Guinea, Rwanda, Senegal, Sierra Leone, Solomon Islands, Somalia, } \\
\text { South Sudan, Sudan, São Tomé and Príncipe, Tajikistan, Tanzania, Togo, Uganda, Uzbekistan, Vietnam, Yemen, Zambia, Zimbabwe }\end{array}$ \\
\hline $\begin{array}{l}\text { Countries and } \\
\text { Territories with } \\
\text { Average Annual } \\
\text { Temperature } \\
\text { above } 15^{\circ} \mathrm{C}\end{array}$ & $\begin{array}{l}\text { Algeria, American Samoa, Angola, Anguilla, Antigua and Barbuda, Argentina, Australia, Bahrain, Bangladesh, Barbados, Belize, Benin, Bhutan, } \\
\text { Botswana, Brazil, Brunei Darussalam, Burkina Faso, Burundi, Cabo Verde, Cambodia, Cameroon, Central African Republic, Chad, Colombia, } \\
\text { Comoros, Democratic Republic of the Congo, Republic of Congo, Costa Rica, Cuba, Curaçao, }{ }^{*} \text { Cyprus, Côte d'Ivoire, Djibouti, Dominica, } \\
\text { Dominican Republic, Ecuador, Egypt, El Salvador, Equatorial Guinea, Eritrea, Ethiopia, Fiji, Gabon, The Gambia, Ghana, Grenada, Guadeloupe, }{ }^{\star} \\
\text { Guatemala, French Guiana, }{ }^{*} \text { Guinea, Guinea-Bissau, Guyana, Haiti, Honduras, India, Indonesia, Iraq, Israel, Jamaica, Jordan, Kenya, Kuwait, } \\
\text { Lao P.D.R., Lebanon, Liberia, Libya, Madagascar, Malawi, Malaysia, Mali, Malta, Martinique, }{ }^{\star} \text { Mauritania, Mauritius, Mexico, Montserrat, } \\
\text { Morocco, Mozambique, Myanmar, Namibia, Nepal, New Caledonia, Nicaragua, Niger, Nigeria, Oman, Pakistan, Panama, Papua New Guinea, } \\
\text { Paraguay, Philippines, Puerto Rico, Qatar, Reunion, }{ }^{*} \text { Rwanda, Samoa, Saudi Arabia, Senegal, Sierra Leone, Singapore, Solomon Islands, } \\
\text { Somalia, South Africa, South Sudan, Sri Lanka, St. Kitts and Nevis, St. Lucia, St. Vincent and the Grenadines, Sudan, Suriname, Swaziland, } \\
\text { Syria, São Tomé and Príncipe, Tanzania, Thailand, Timor-Leste, Togo, Tonga, Trinidad and Tobago, Tunisia, Turkmenistan, Turks and Caicos, }{ }^{*} \\
\text { Uganda, United Arab Emirates, Uruguay, Vanuatu, Venezuela, Vietnam, Virgin Islands (US), West Bank and Gaza, Yemen, Zambia, Zimbabwe }\end{array}$ \\
\hline $\begin{array}{l}\text { Countries with } \\
\text { Sectoral-Level } \\
\text { Data }\end{array}$ & $\begin{array}{l}\text { Argentina, Bolivia, Botswana, Brazil, Chile, China, Colombia, Costa Rica, Denmark, Egypt, Ethiopia, France, Germany, Ghana, Hong Kong SAR, }{ }^{*} \\
\text { India, Indonesia, Italy, Japan, Kenya, Korea, Malawi, Malaysia, Mauritius, Mexico, Morocco, Netherlands, Nigeria, Peru, Philippines, Senegal, } \\
\text { Singapore, South Africa, Spain, Sweden, Taiwan Province of China, }{ }^{*} \text { Tanzania, Thailand, United Kingdom, United States, Venezuela, Zambia }\end{array}$ \\
\hline
\end{tabular}




\section{AnNeX 2. Model-BaSed ANALYSiS}

The model used to analyze the long-term impact of climate change is developed and presented in Buffie et al. (2012). It is commonly known as the Debt, Investment and Growth (DIG) model and has served as a workhorse in many IMF studies of low-income countries. The DIG is an optimizing intertemporal model with perfect foresight. It describes a twosector small open economy model with private and public capital, learning by doing, and endogenous fiscal policies. Public capital is productive and is used in the production function in both sectors. Government spending can raise output directly by augmenting the stock of public capital and can crowd in as well as crowd out private investment.

Firms operate Cobb-Douglas technologies to combine labor, private capital, and public capital (infrastructure) into output in the traded and nontraded sectors. The evolution of total factor productivity (TFP) is exogenous in both sectors. Firms face separate prices for exports, and imports and are assumed to be profit maximizing.

Consumers supply labor and derive utility from consuming the domestic traded good, the foreign traded good, and the domestic nontraded good. These goods are combined into a constant elasticity of substitution basket, and savers maximize the present value of their lifetime utility. The model breaks Ricardian equivalence by including both savers and handto-mouth consumers.

The government spends on transfers, debt service, and (partially inefficient) infrastructure investment. It collects revenue from the consumption value-added tax (VAT) and from user fees for infrastructure services. The deficit is financed through domestic borrowing, external concessional borrowing, or external commercial borrowing. Policymakers accept all concessional loans offered by official creditors. The borrowing and amortization schedule for these loans is fixed exogenously. Debt sustainability requires that the VAT and transfers eventually adjust to cover the entire deficit, given the exogenously determined upper limit on taxes and lower limit on transfers. The model incorporates shocks to the government external debt risk premium (or world interest rates).

The majority of the model parameters are set to the same values as in Buffie et al. (2012), with few exceptions, mostly to reflect the decline in global interest rates, the projection of trend GDP growth in low-income countries, and the sample median of public-debt-to-GDP ratios. The parameters that differ from the ones in Buffie et al. (2012) are presented in Annex Table 2.1.

Annex Table 2.1. Parameterization of the Debt, Investment, and Growth Model

\begin{tabular}{lc}
\hline Parameter & Value (percent) \\
\hline Initial Return on Infrastructure Investment & 30 \\
Public Domestic Debt-to-GDP Ratio & 10 \\
Public Concessional Debt-to-GDP Ratio & 30 \\
Public External Commercial Debt-to-GDP Ratio & 5 \\
Oil Revenues-to-GDP Ratio & 2 \\
Real Interest Rate on Public Domestic Debt & 7 \\
Real Interest Rate on Public External Commercial Debt & 4 \\
Trend per Capita Growth Rate & 2.8 \\
\hline Sources: Buffie &
\end{tabular}




\section{Simulating the Long-Term Impacts of Climate Change}

To trace the long-term impact of climate change, the model incorporates the estimated relationship between temperature and per capita output presented in Table 1, column (5). The effect is assumed to occur through temperature's effect on TFP; therefore, the estimated parameters are rescaled so that the model matches the empirically estimated decline of GDP if temperature increases by $1{ }^{\circ} \mathrm{C}$. Estimates of the damage to GDP cannot be used directly since GDP is endogenous.

The temperature during 2017-2100 is assumed to follow one of two alternative scenarios: Representative Concentration Pathway (RCP) 4.5 or RCP 8.5. The temperature increases during 2017-2100 are calculated for the median low-income country in the sample and are equal to $2.0^{\circ} \mathrm{C}$ and $3.9^{\circ} \mathrm{C}$ for RCP 4.5 and RCP 8.5 , respectively.

\section{Modeling Structural Transformation}

Structural transformation is generated in the DIG model by introducing diverging trends in sectoral TFP growth, along the lines of Ngai and Pissarides (2007). In their model, faster productivity growth in the traded good sector goes along with a decline in the relative price of traded versus nontraded goods. Given complementarity in final demand, production in the former sector relative to the latter does not increase in the same proportion. The value share of the traded good sector eventually shrinks, even in the presence of international trade. While this approach relies on only one potential driver of structural transformation, it generates the desired increase in employment and nominal-value-added shares of the nontraded goods sector, which is mostly composed of services. The gap in sectoral TFP growth rates is set to replicate the average increase in the service share of value added in LIDCs in the period 1990-2015, which has risen at the rate of 2.5 percentage points a decade. Given this calibration, in the scenario without rising temperatures the employment share of nontraded goods increases from the baseline value of 42.27 to 65 percent over 90 years. 


\section{REFERENCES}

Anthoff, David, and Richard Tol. 2010. "FUND-Climate Framework for Uncertainty, Negotiation and Distribution."

Auffhammer, Maximilian, Solomon M. Hsiang, Wolfram Schlenker and Adam Sobel. 2011. "Global Climate Models and Climate Data: A User Guide for Economists." Unpublished.

Barreca, Alan I. 2012. "Climate Change, Humidity, and Mortality in the United States." Journal of Environmental Economics and Management 63 (1): 19-34.

—_, Karen Clay, Olivier Deschênes, Michael Greenstone, and Joseph Shapiro. 2016. "Adapting to Climate Change: The Remarkable Decline in the US TemperatureMortality Relationship over the 20th Century." Journal of Political Economy 124 (1): $105-59$.

Barrios, Salvador, Luisito Bertinelli, and Eric Strobl. 2006. "Climatic Change and RuralUrban Migration: The Case of Sub-Saharan Africa." Journal of Urban Economics 60 (3): $357-71$.

- 2010. "Trends in Rainfall and Economic Growth in Africa: A Neglected Cause of the African Growth Tragedy." Review of Economics and Statistics 32 (2): 350-66.

Barrios, Salvador, Ouattara Bazoumana, and Eric Strobl. 2008. "The Impact of Climatic Change on Agricultural Production: Is It Different for Africa?" Food Policy 33: 28798.

Buckley, B. M., K. J. Anchukaitis, D. Penny, R. Fletcher, E. R. Cook, M. Sano, C. Nam le, A. Wichienkeeo, T. T. Minh, and T. M. Hong. 2010. "Climate as a Contributing Factor in the Demise of Angkor, Cambodia." Proceedings of the National Academy of Sciences 107 (15): 6748-52.

Buffie, Edward, Andrew Berg, Catherine Pattillo, Rafael Portillo, and Luis-Felipe Zanna. 2012. "Public Investment, Growth, and Debt Sustainability: Putting Together the Pieces." IMF Working Paper 12/144, International Monetary Fund, Washington, DC.

Büntgen, U., W. Tegel, K. Nicolussi, M. McCormick, D. Frank, V. Trouet, J. O. Kaplan, Franz Herzig, Karl-Uwe Heussner, Heinz Wanner, Jürg Luterbacher, and Jan Esper. 2011. "2500 Years of European Climate Variability and Human Susceptibility." Science 331 (6017): 578-82.

Burgess, Robin, Olivier Deschênes, Dave Donaldson, and Michael Greenstone. 2014. "The Unequal Effects of Weather and Climate Change: Evidence from Mortality in India." Unpublished. 
Burke, Marshall, Solomon M. Hsiang, and Edward Miguel. 2015a. "Global Non-Linear Effect of Temperature on Economic Production." Nature 527:235-39.

_. 2015b. "Climate and Conflict." Annual Review of Economics 7: 577-617.

Burke, Marshall, John Dykema, David Lobell, Edward Miguel, and Shanker Satyanath. 2015. "Incorporating Climate Uncertainty into Estimates of Climate Change Impacts, with Applications to U.S and African Agriculture." Review of Economics and Statistics 97(2): 461-471.

Burke, Marshall, and Kyle Emerick. 2016. "Adaptation to Climate Change: Evidence from US Agriculture.” American Economic Journal: Economic Policy 8(3): 106-40.

Burke, Paul J., and Andrew Leigh. 2010. "Do Output Contractions Trigger Democratic Change?" American Economic Journal: Macroeconomics 2 (4): 124-57.

Carleton, Tamma A., and Solomon M. Hsiang. 2016. "Social and Economic Impacts of Climate." Science 353 (6304).

Cashin, Paul, Kamiar Mohaddes, and Mehdi Raissi. 2017. "Fair Weather or Foul? The Macroeconomic Effects of El Niño.” Journal of International Economics 106: 37-54.

Center for International Earth Science Information Network (CIESIN) Columbia University. 2016. Gridded Population of the World, Version 4 (GPWv4): Population Count. NASA Socioeconomic Data and Applications Center (SEDAC), Palisades, NY. http://dx.doi.org/10.7927/H4X63JVC. Accessed March 15, 2017.

- United Nations Food and Agriculture Programme (FAO), and Centro Internacional de Agricultura Tropical (CIAT). 2005. Gridded Population of the World, Version 3 (GPWv3): Population Count Grid. NASA Socioeconomic Data and Applications Center (SEDAC), Palisades, NY. http://dx.doi.org/10.7927/H4639MPP. Accessed March 15, 2017.

Chaney, Eric. 2013. "Revolt on the Nile: Economic Shocks, Religion, and Political Power." Econometrica 81: 2033-53.

Colmer, Jonathan. 2016. "Weather Labor Reallocation and Industrial Production: Evidence from India.” Unpublished, MIT, Cambridge, MA.

Costinot, Arnaud, Dave Donaldson, and Cory Smith. 2016. "Evolving Comparative Advantage and the Impact of Climate Change in Agricultural Markets: Evidence from 1.7 Million Fields around the World." Journal of Political Economy 124 (1): 205-48. 
Cullen, H., P. B. deMenocal, S. Hemming, G. Hemming, F. H. Brown, T. Guilderson, and F. Sirocko. 2000. "Climate Change and the Collapse of the Akkadian Empire: Evidence from the Deep Sea." Geology 28 (4): 379-82.

Dell, Melissa, Benjamin F. Jones, and Benjamin A. Olken. 2012. "Temperature Shocks and Economic Growth: Evidence from the Last Half Century." American Economic Journal: Macroeconomics 4 (3): 66-95.

- 2014. "What Do We Learn from the Weather? The New Climate-Economy Literature." Journal of Economic Literature 52 (3): 740-98.

Deryugina, Tatyana, and Solomon M. Hsiang. 2014. "Does the Environment Still Matter? Daily Temperature and Income in the United States." NBER Working Paper 20750, National Bureau of Economic Research, Cambridge, MA.

Deschênes, Olivier. 2012. "Temperature, Human Health and Adaptation: A Review of the Empirical Literature.” NBER Working Paper 18345, National Bureau of Economic Research, Cambridge, MA.

_, and Michael Greenstone. 2011. "Climate Change, Mortality, and Adaptation: Evidence from Annual Fluctuations in Weather in the US." American Economic Journal: Applied Economics 3 (4): 152-85.

Fankhauser, Samuel, and Richard Tol. 2005. "On Climate Change and Economic Growth." Resource and Energy Economics 27: 1-17.

Farid, Mai, Michael Keen, Michael Papaioannou, Ian Parry, Catherine Pattillo, and Anna Ter-Martirosyan. 2016. “After Paris: Fiscal, Macroeconomic, and Financial Implications of Climate Change." IMF Staff Discussion Note 16/01, International Monetary Fund, Washington, DC.

Feng, Shuaizhang, Alan B. Krueger, and Michael Oppenheimer. 2010. "Linkages among Climate Change, Crop Yields, and Mexico-US Cross-Border Migration." Proceedings of the National Academy of Sciences 107 (32): 14257-62.

Feng, Shuaizhang, Michael Oppenheimer, and Wolfram Schlenker. 2012. "Climate Change, Crop Yields, and Internal Migration in the United States.” NBER Working Paper 17734, National Bureau of Economic Research, Cambridge, MA.

Füssel, Hans-Martin. 2010. "Modeling impacts and adaptation in global IAMs.” Wiley Interdisciplinary Reviews: Climate Change 1 (2): 288-303.

Garg, Teevrat, Maulik Jagnani, and Viz Taraz. 2017. "Human Capital Costs of Climate Change: Evidence from Test Scores in India.” Unpublished. 
Graff Zivin, Joshua S., Solomon M. Hsiang, and Matthew J. Neidell. 2015. “Temperature and Human Capital in the Short- and Long-Run.” NBER Working Paper 21157, National Bureau of Economic Research, Cambridge, MA.

Graff Zivin, Joshua S., and Matthew J. Neidell. 2014. "Temperature and the Allocation of Time: Implications for Climate Change.” Journal of Labor Economics 32 (1): 1-26.

Guo, Y., A. Gasparrini, B. Armstrong, S. Li, B. Tawatsupa, A. Tobias, E. Lavigne, M. de Sousa Zanotti Stagliorio Coelho, M. Leone, X. Pan, S. Tong, L. Tian, H. Kim, M. Hashizume, Y. Honda, YL Guo, CF Wu, K. Punnasiri, SM Yi, P. Michelozzi, PH Saldiva, and G. Williams. 2014. "Global Variation in the Effects of Ambient Temperature on Mortality: A Systematic Evaluation.” Epidemiology 25 (6): 781-89.

Hallegatte, Stéphane. 2009. "Strategies to Adapt to an Uncertain Climate Change." Global Environmental Change 19 (2): 240-47.

-, M. Bangalore, L. Bonzanigo, M. Fay, T. Kane, U. Narloch, J. Rozenberg, D. Treguer, and A. Vogt-Schilb. 2016. Shock Waves: Managing the Impacts of Climate Change on Poverty. Climate Change and Development Series. Washington, DC: World Bank.

— Jean-Charles Hourcade, Patrice Dumas. 2007. "Why Economic Dynamics Matter in Assessing Climate Change Damages: Illustration on Extreme Events." Ecological Economics 62: 330-40.

— Climate Change 4: 250-56.

Haug, Gerald H., Detlef Günther, Larry C. Peterson, Daniel M. Sigman, Konrad A. Hughen, and Beat Aeschlimann. 2003. "Climate and the Collapse of Maya Civilization." Science 299 (5613): 1731-35.

Heal, Geoffrey, and Jisung Park. 2016. "Temperature Stress and the Direct Impact of Climate Change: A Review of an Emerging Literature." Review of Environmental Economics and Policy 10 (2): 347-62.

Hope, Chris. 2011. "The PAGE09 Integrated Assessment Model: A Technical Description." Cambridge Judge Business School Working Papers 4/11.

Hsiang, Solomon M. 2016. "Climate Econometrics.” Annual Review of Resource Economics 8: $43-75$.

Intergovernmental Panel on Climate Change (IPCC). 2013. Climate Change 2013: The Physical Science Basis. Summary for Policymakers. Contribution of Working Group 
I to the Fifth Assessment Report of the Intergovernmental Panel on Climate Change. Cambridge, U. K. and New York, NY: Cambridge University Press.

- 2014. Climate Change 2014: Impacts, Adaptation, and Vulnerability. Part A: Global and Sectoral Aspects. Contribution of Working Group II to the Fifth Assessment Report of the Intergovernmental Panel on Climate Change. Cambridge, U.K., and New York, NY: Cambridge University Press.

International Monetary Fund (IMF). 2015. "Macroeconomic Developments and Prospects in Low-Income Developing Countries.” Policy Paper, Washington, DC.

—. 2016a. "Enhancing Resilience to Natural Disasters in Sub-Saharan Africa." In Regional Economic Outlook: Sub-Saharan Africa. Washington DC, Fall.

—. 2016b. "Small States' Resilience to Natural Disasters and Climate Change: Role for the IMF." Board Paper, Washington, DC.

Jordà, Òscar. 2005. "Estimation and Inference of Impulse Responses by Local Projections." American Economic Review 95 (1): 161-82.

Kelley, Colin P., Shahrzad Mohtadi, Mark A. Cane, Richard Seager, and Yochanan Kushnir. 2015. "Climate Change in the Fertile Crescent and Implications of the Recent Syrian Drought." Proceedings of the National Academy of Sciences 112 (11): 3241-46.

Kim, Nam Kyu. 2014. "Revisiting Economic Shocks and Coups.” Journal of Conflict Resolution 60: 3-31.

Klein Goldewijk, K., A. Beusen, J. Doelman and E. Stehfest. 2016. "New Anthropogenic Land Use Estimates for the Holocene; HYDE 3.2."

Kudamatsu, Masayuki, Torsten Persson, and David Strömberg. 2012. "Weather and Infant Mortality in Africa.” CEPR Discussion Paper 9222, Centre for Economic Policy Research, London.

Lanzafame, Matteo. 2014. "Temperature, Rainfall and Economic Growth in Africa." Empirical Economics 46 (1): 1-18.

Lee, Minsoo, Mai Lin Villaruel, and Raymond Gaspar. 2016. "Effects of Temperature Shocks on Economic Growth and Welfare in Asia.” ADB Economics Working Paper 501, Asian Development Bank, Mandaluyong City, Philippines.

Lemoine, Derek. 2017. "Expect Above Average Temperatures: Identifying the Economic Impact of Climate Change.” NBER Working Paper 23549, National Bureau of Economic Research, Cambridge, MA. 
Lobell, David B., Wolfram Schlenker, and Justin Costa-Roberts. 2011. "Climate Trends and Global Crop Production since 1980.” Science 333 (6042): 616-20.

Marcott, Shaun A., Jeremy D. Shakun, Peter U. Clark, and Alan C. Mix. 2013. “A Reconstruction of Regional and Global Temperature for the Past 11,300 Years." Science 339 (6124): 1198-201.

Matsuura, Kenji, and Cort J. Willmott. 2007. “Terrestrial Air Temperature: 1900-2006 Gridded Monthly Time Series (Version 1.01) 2009."

National Oceanic and Atmospheric Administration (NOAA). 2017. "Climate at a Glance: Global Time Series." National Centers for Environmental Information, NOAA, Department of Commerce, Washington, DC. http://www.ncdc.noaa.gov/cag/.

Ngai, L. Rachel, and Christopher A. Pissarides. 2007. "Structural Change in a Multi-Sector Model of Growth.” American Economic Review 97 (1): 429-443.

Niemelä, Raimo, Mika Hannula, Sari Rautio, Kari Reijula, and Jorma Railio. 2002. "The Effect of Air Temperature on Labour Productivity in Call Centres-A Case Study." Energy and Buildings 34 (8): 759-64.

Nordhaus, William D. 2010. "Economic Aspects of Global Warming in a Post-Copenhagen Environment." Proceedings of the National Academy of Sciences 107 (26): 11721-26.

- 2016. "Projections and Uncertainties About Climate Change in an Era of Minimal Climate Policies.” NBER Working Paper 22933, National Bureau of Economic Research, Cambridge, MA. , and Andrew Moffat. 2017. "A Survey of Global Impacts of Climate Change: Replication, Survey Methods and a Statistical Analysis." NBER Working Paper 23646, National Bureau of Economic Research, Cambridge, MA.

— , and Paul Sztorc. 2013. "DICE 2013R: Introduction and User’s Manual.” www.dicemodel.net.

Park, Jisung. 2017. "Heat Stress and Human Capital Production.” Unpublished, Harvard University, Cambridge, MA.

Roston, Eric, and Blacki Migliozzi. 2015. "What's Really Warming the World?” Bloomberg Business Week, June 24.

Schlenker, Wolfram, and David B. Lobell. 2010. "Robust Negative Impacts of Climate Change on African Agriculture.” Environmental Research Letters 5 (1). 
Schlenker, Wolfram, and Michael J. Roberts. 2009. "Nonlinear Temperature Effects Indicate Severe Damages to U.S. Crop Yields under Climate Change." Proceedings of the National Academy of Sciences 106 (37): 15594-98.

Seppänen, Olli, William J. Fisk, and David Faulkner. 2003. "Cost Benefit Analysis of the Night-Time Ventilative Cooling in Office Building.” Lawrence Berkeley National Laboratory.

Seppänen, Olli, William J. Fisk, and Q. H. Lei. 2006. "Room Temperature and Productivity in Office Work.” LBNL-60952. Lawrence Berkeley National Laboratory, Berkeley, CA.

Shakun, Jeremy D., Peter U. Clark, Feng He, Shaun A. Marcott, Alan C. Mix, Zhengyu Liu, Bette Otto-Bliesner, Andreas Schmittner, and Edouard Bard. 2012. "Global Warming Preceded by Increasing Carbon Dioxide Concentrations during the Last Deglaciation." Nature 484: 49-54.

Somanathan, Eswaran, Rohini Somanathan, Anant Sudarshan, and Meenu Tewari. 2017. "The Impact of Temperature on Productivity and Labor Supply: Evidence from Indian Manufacturing." Unpublished.

Stern, Nicholas Herbert. 2007. The Economics of Climate Change: The Stern Review. Cambridge University Press.

- 2015. Why Are We Waiting? The Logic, Urgency, and Promise of Tackling Climate Change. Cambridge, MA: MIT Press.

Stock, James H., and Mark W. Watson. 2007. "Why Has U.S. Inflation Become Harder to Forecast?" Journal of Money, Credit and Banking 39 (S1): 3-33.

Teulings, Coen N., and Nikolay Zubanov. 2014. "Is Economic Recovery a Myth? Robust Estimation of Impulse Responses." Journal of Applied Econometrics 29 (3): 497-514.

Timmer, Marcel P., Gaaitzen de Vries, and Klaas de Vries. 2015. "Patterns of Structural Change in Developing Countries." In Routledge Handbook of Industry and Development, edited by John Weiss and Michael Tribe, 65-83. London: Routledge.

Tol, Richard S. 2009. "The Economic Effects of Climate Change." Journal of Economic Perspectives, 23 (2): 29-51.

- 2014. "Correction and Update: The Economic Effects of Climate Change." Journal of Economic Perspectives 28 (November): 221-26.

Wang, Sun Ling, Eldon Ball, Richard Nehring, Ryan Williams, and Truong Chau. 2017. "Impacts of Climate Change and Extreme Weather on U.S. Agricultural 
Productivity." NBER Working Paper 23533, National Bureau of Economic Research, Cambridge, MA.

Wargocki, Pawel, and David P. Wyon. 2007. "The Effects of Moderately Raised Classroom Temperatures and Classroom Ventilation Rate on the Performance of Schoolwork by Children (RP-1257).” HVAC\&R Research 13 (2): 193-220.

Weitzman, Martin. 2011. "Fat-Tailed Uncertainty in the Economics of Catastrophic Climate Change." Review of Environmental Economics and Policy 5 (2): 275-92.

World Bank. 2013. Turn Down the Heat: Climate Extremes, Regional Impacts, and the Case for Resilience. A report for the World Bank by the Potsdam Institute for Climate Impact Research and Climate Analytics. Washington, DC: World Bank. 